\title{
Using the Predicted Structure of the Amot Coiled Coil Homology Domain to Understand Lipid Binding
}

\author{
Cameron Peck, Piia Virtanen, Dr. Derrick Johnson \\ Faculty Mentor: Dr. Ann C. Kimble-Hill, Indiana University School of Medicine
}

\begin{abstract}
Angiomotins (Amots) are a family of adapter proteins that modulate cellular polarity, differentiation, proliferation, and migration. Amot family members have a characteristic lipid-binding domain, the coiled coil homology (ACCH) domain that selectively targets the protein to membranes, which has been directly linked to its regulatory role in the cell. Several spot blot assays were used to validate the regions of the domain that participate in its membrane association, deformation, and vesicle fusion activity, which indicated the need for a structure to define the mechanism. Therefore, we sought to understand the structure-function relationship of this domain in order to find ways to modulate these signaling pathways. After many failed attempts to crystallize the ACCH domain of each Amot family member for structural analysis, we decided to pursue homologous models that could be refined using small angle x-ray scattering data. Theoretical models were produced using the homology software SWISS-MODEL and threading software I-TASSER and LOMETS, followed by comparison to SAXS data for model selection and refinement. We present a theoretical model of the domain that is driven by alpha helices and short random coil regions. These alpha helical regions form a classic dimer interface followed by two wide spread legs that we predict to be the lipid binding interface.
\end{abstract}

KEYWORDS: Amot, ACCH domain, I-TASSER, LOMETS, SAXS, peptide tile, spot blot, theoretical structure

\section{INTRODUCTION}

$\mathrm{T}$ he Angiomotin (Amot) families of proteins are key regulators in cellular growth, differentiation, and proliferation via the MAPK, VEGF, and HIPPO signaling pathways (Aase et al., 2007; Chan et al., 2011; Ernkvist et al., 2006; Hirate et al., 2013; Hirate \& Sasaki, 2014; Levchenko et al., 2008; Mana-Capelli, Paramasivam, Dutta, \& McCollum, 2014; Ortiz et al., 2015; Ranahan et al., 2011; Shimono \& Behringer, 2003; Sugihara-Mizuno et al., 2007; W. Wang, Huang, \& Chen, 2011; Wells et al., 2006; Zhao et al., 2011; Zheng et al., 2009). Understanding the function of this family has been shown to be important as their overexpression and functional dysregulation is linked to the initiation and/or progression of many cancers including renal (Lv et al., 2016), highly invasive and metastatic breast tumors (Jiang, Watkins, Douglas-Jones, Holmgren, \& Mansel, 2006; Ranahan et al., 2011; H. Zhang \& Fan, 2015), osteosarcoma (W.-D. Ruan, Wang, Feng, Xue, \& Zhang, 2016; W. Ruan, Wang,
Feng, Xue, \& Li, 2016), prostate (Albrecht, Green, \& Dubash, 2016), head and neck (Hakami et al., 2014), liver (Yi et al., 2013), ovarian (Y. Wang et al., 2017), lung (Hsu et al., 2015), and gastrointestinal (Ellmark et al., 2006). Members of this family often have opposing activities while sharing similar domain features. One such feature is the presence of a coiled-coil homology domain (ACCH) that has been shown to have a membrane binding and joining activity (Ernkvist et al., 2008; Hirate et al., 2013). The Amot80/130 ACCH domain shares over $68 \%$ and $56 \%$ sequence identity with the other two family members, AmotL1 and AmotL2 respectively (Heller et al., 2010). Specifically, the Amot80/130 ACCH domain has been shown to have selective affinities towards mono-phosphorylated phosphatidylinositol (PI) and cholesterol containing membranes (Heller et al., 2010; McLaughlin, Wang, Gambhir, \& Murray, 2002), which are key lipids in maintaining cellular polarity and membrane protein targeting as well as overall normal cell function. While several

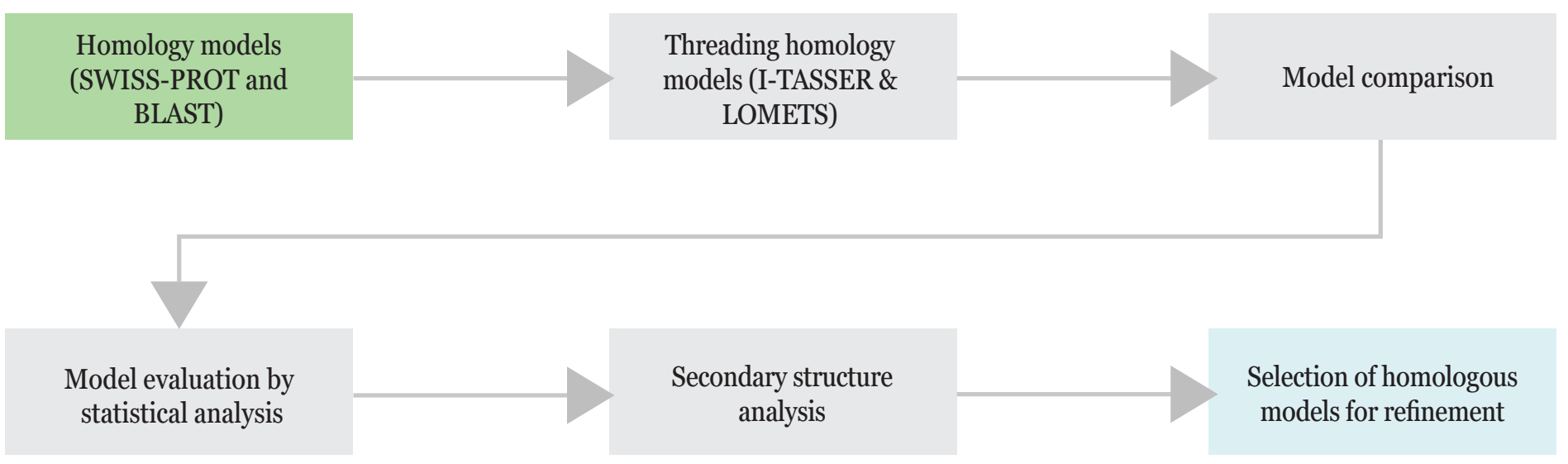

Figure 1.

Threading methodology. Flow chart showing methodology and steps for threading modeling process. 
well-known domains also contain selective affinity for PI lipids, none of them have been reported to have membrane joining activity (T. F. Franke, Kaplan, Cantley, \& Toker, 1997; Leevers, Vanhaesebroeck, \& Waterfield, 1999; Rong et al., 2001; Harald Stenmark, Aasland, Toh, \& D’Arrigo, 1996; H. Stenmark \& Gillooly, 2001; Vanhaesebroeck \& Waterfield, 1999; Y Xu, Seet, Hanson, \& Hong, 2001). This domain is also positionally conserved with BAR domains, including that of amphiphysin. BAR domains are known to associate with membranes, but in contrast to the ACCH domain they are generally non-selective in lipid composition targeting and drive exocytosis events (Dawson, Legg, \& Machesky, 2006; Gallop et al., 2006; Peter et al., 2004). The crystal structures of several BAR domains suggest a concave shape that allows them to bind to membranes. However, the ACCH domain does not have the residues typically associated with a BAR domain function. These highlighted differences in predicted structure and functional activity of this domain suggest a need for detailed structural analysis of the ACCH domain. Attempts to obtain a crystal structure have been unsuccessful, leading to a study that included structure prediction by homology (SWISS-MODEL and BLAST) and threading (I-TASSER and LOMETS) model building, followed by refinement of the predicted structure with data generated from small angle $\mathrm{x}$-ray scattering (SAXS) (Figure 1). We compared these models against the results from lipid binding assays that suggested three regions of importance to hypothesize a mechanism for $\mathrm{ACCH}$ domain activity. These results potentially have implications for further understanding the activity of unique BAR domains and Amot's specific vesicle fusion mechanism.

\section{MATERIALS \& METHODS Protein Purification}

We used the following methodology to make purified $\mathrm{ACCH}$ domain protein for experimentation. The Amot ACCH domain cDNA was subcloned into the pGEX expression plasmid and transformed into Escherichia coli BL21 (DE3) cells as previously described (Colwill et al., 2006). Mutations in the DNA sequence were cloned into the vector using Pfu Polymerase AD in a sitedirected mutagenesis polymerase chain reaction (Cha \& Tilly, 1995; Flaman et al., 1994; Lundberg et al., 1991). Cells were grown in 2xTY medium with $100 \mathrm{mg} / \mathrm{L}$ ampicillin at $37^{\circ} \mathrm{C}$. $0.1 \mathrm{mM}$ isopropyl-beta-D-thiogalactopyranoside was used to induce protein synthesis at $16^{\circ} \mathrm{C}$ overnight. Cells were pelleted by centrifugation and solubilized in lysis buffer (phosphate buffered saline solution containing $1 \mathrm{mM}$ DTT, $4 \mathrm{mM}$ Benzamidine, and $24.7 \mu \mathrm{M}$ dodecyl thiomaltopyranoside). $50 \mathrm{~g} / \mathrm{L}$ lysozyme was used to lyse the cells using previously described methodology (Shugar, 1952). Additionally, the solutions were sonicated for 30 minutes followed by boiling for 40 seconds. The lysate was then collected by centrifugation at $15000 \mathrm{rpm}$ at $4^{\circ} \mathrm{C}$ for 30 minutes using a JA-10 rotor. Protein was purified using batch purification of glutathione resin (Ali, Chachadi, Petrosyan, \& Cheng, 2012; Bobba, Ponnaluri, Mukherji, \& Gutheil, 2011; Petrosyan, Ali, Verma, Cheng, \& Cheng, 2012). Overnight thrombin cleavage on the resin separated the GST tag from the protein of interest (Arnau, Lauritzen, Petersen, \& Pedersen, 2006; Terpe, 2003). The protein was eluted from the resin using a buffer of $50 \mathrm{mM}$ Tris, 600 mM HEPES, 300 mM NaCl, 0.5 mM EDTA, 1 mM DTT, 4 mM Benzamidine, $24.7 \mu \mathrm{M}$ dodecyl thiomaltopyranoside, and $50 \mathrm{mM}$ glutathione. The proteins were concentrated using a $10 \mathrm{kDa}$ filter centrifugal tube to $\geq 32 \mu \mathrm{M}$. Protein purity was analyzed using SDS-PAGE. In short, we utilized bacterial cultures to produce large quantities of the tagged protein that were purified by the tag's selective affinity. We used this protein for all experiments highlighted within this paper.

\section{Spot Blot Array Assays}

Liposomes were constructed using previously described methods for their use in determining which sections of the $\mathrm{ACCH}$ domain had the highest probability of direct interaction (Johnson, Seifert, Petrache, \& Kimble-Hill, 2014). Lyophilized lipid (POPC/POPE/Chol/PI4P/ DOPE-biotinylated cap 59/16/16/5/4 mol\%) was hydrated in $50 \mathrm{mM}$ Tris, 600 mM HEPES, 300 mM NaCl, 0.5 mM EDTA, 1 mM DTT, 4 mM Benzamidine, and $24.7 \mu \mathrm{M}$ dodecyl thiomaltopyranoside buffer that contained $0.5 \mathrm{~g} / \mathrm{L}$ Alexa Fluor 790 Streptavidin (Invitrogen) for a final lipid concentration of $25 \mathrm{mM}$. After rinsing, the amount of liposomes bound to each spot is determined by the Alexa Fluor 790 fluorescence and imaged using a LICOR imaging station, where the intensity is quantified using Odyssey v1.2.

SPOTs synthesis. Peptide arrays were constructed using the SPOTs synthesis as previously described (Ashpole \& Hudmon, 2011). Following synthesis and de-protection, the peptide membrane is blocked at room temperature for thirty minutes in binding buffer (20mM Tris pH 7.4, 200mM NaCl, 1mM EDTA and 0.1\% Tween-20) with $5 \%$ BSA. SPOTs membranes incubated for 10 minutes in blocking buffer containing $5 \mu \mathrm{M}$ lipid, followed by washing in binding buffer, and LICOR scanning.

SPOTs lipid binding assay. Protein at concentrations from 0-50 $\mu \mathrm{M}$ were blotted onto nitrocellulose, followed by blocking for 30 minutes with a $5 \%$ milk, $0.1 \%$ Triton-x in phosphate buffered saline solution (PBST). Membrane was then incubated for 30 minutes in blocking buffer containing $5 \mu \mathrm{M}$ lipid, followed by washing in PBST and scanning of membrane on LICOR. PI4P and cholesterol were incorporated into the lipid mixture to determine the lipid affinity of each peptide as they have both been reported to increase the affinity of the ACCH domain for liposomes (Heller et al., 2010). Alexa Fluor 790 was bound by a streptavidin linkage to biotinylated DHPE so that liposomes could be detected and quantified by fluorescence imaging. The amount of binding is then reported as percentage of the fluorescence intensity with respect to the intensity of lipids bound to the full protein. Additionally, fluorescence intensity of commercially available bovine serum albumin bound to the PI4P vesicles was used as negative control and had no detectable fluorescence. The lipid affinity for each protein was determined by the Langmuir adsorption isotherm for fractional membrane coverage, $\theta=\mathrm{cK}_{\mathrm{L}} /\left(1+\mathrm{cK}_{\mathrm{L}}\right)$, where $\mathrm{c}$ is the protein concentration and $\mathrm{K}_{\mathrm{L}}$ is the equilibrium binding constant (Hinderliter \& May, 2006).

\section{Small Angle X-ray Scattering (SAXS)}

Scattering data was used to generate globular envelope dimensions and refine predicted structure models. Guinier analysis was used to generate both globular spherical and long cylinder envelope models. Initial models were used to generate dummy bead models designed for comparison against theoretical models. This comparison served the purpose of confirming that the theoretical models fit the globular envelope suggested by the SAXS data. Background subtracted SAXS data was used to refine predicted structure models by evaluating fit parameters against several different globular envelope shapes, the average of which was used to generate more refined dummy bead models. These models were further compared to the theoretical models and refined for fit with the ACCH Domain. 
SAXS measurements. Measurements were performed at the Advanced Photon Source (APS/ANL) beamline 12-ID-B and 12ID-C. The pinhole setup at 12-ID-C used a photon energy of $12 \mathrm{KeV}$ and a custom-built 4-quadrant mosaic X-ray CCD camera Platinum detector (1024x1024 pixel). The sample-to-detector distance was $\sim 2.2 \mathrm{~m}$ and had a flux of approximately $5 \times 1012$ photons/second. Samples were measured as suspended droplets for $0.1 \mathrm{~s}$ at $\sim 23^{\circ} \mathrm{C}$ for $0.1 \mathrm{~s}$. 2D scattering data for 5 shots were averaged and integrated over the chi angle to obtain intensity versus $q(\AA-1)$.

Guinier analysis. The globular envelope dimensions were determined by performing Guinier analysis, where the data were fit to both a sphere and a long cylinder model (Flory \& Volkenstein, 1969). The low q Guinier plot has been described elsewhere and is used to approximate the spherical radius of gyration from the slope of a plot of $\mathrm{I}(\mathrm{q})=\mathrm{I}_{0} \exp \left(-\mathrm{Q}^{2} \mathrm{R}_{\mathrm{q}}^{2} / 3\right)$. The radius of a sphere has been described as $r^{2}=5 / 3 R_{g}^{2}$. For a long rod or cylinder, the intermediate q-range is used to determine the radius as defined by the slope of a plot of $\mathrm{I}(\mathrm{q})=\left(\mathrm{I}_{0} / \mathrm{q}\right) \exp \left(-\mathrm{Q} 2 \mathrm{R}_{\mathrm{g}}{ }^{2} / 2\right)$. In this model, the radius of the rod is related to this intermediate radius of gyration has been described as $r^{2}=5 / 3 R_{\mathrm{g}}^{2}$, while the low q radius of gyration has been used to determine the length, $\mathrm{L}^{2}=12 \mathrm{R}_{\mathrm{g}}^{2}$.

Predicted structure model refinement. Background subtracted data was then processed and refined the data using the ATSAS suite of programs (version 2.5.2) from European Molecular Biology Laboratory as previously described (Dmitri I. Svergun, Petoukhov, \& Koch, 2001). In short, the background subtracted data was used in GNOM to evaluate the particle distance distribution function and to model fit parameters to several globular shapes (D. Svergun, 1992). $A b$ initio dummy bead models were then created using DAMMIN, DAMMIF, and GASBOR (ATSAS online) followed by alignment into an average model by automated DAMAVER (D. Franke \& Svergun, 2009; D. I. Svergun, 1999; Dmitri I. Svergun et al., 2001; Volkov \& Svergun, 2003). Theoretical models generated from homology and threading models were then compared against the dummy bead models from DAMAVER using CRYSOL for similarity in globular dimensions (D. Svergun, Barberato, \& Koch, 1995). Selected models were then globularly refined by aligning the chain of residues to the dummy bead model using SUPCOMB (Kozin \& Svergun, 2001), followed by topology and residue-based alignment of peptide regions against the dummy bead model using Coot v0.6.1 refine the model further. In summary, refined globular envelope models were generated using SAXS-derived predicted structure and theoretical models.

\section{Template Identification}

Homology and threading online software programs are becoming increasingly popular resources for structure predication of proteins that are difficult to crystallize. Homology modeling programs use the Protein Data Bank (PDB) to determine proteins that are similar in sequence to the test protein and outputs of a list of these matches. However, not all test proteins have clear relatives currently existent in the PDB. For these test proteins, threading, or fold recognition modeling, works much better. Threading software programs predict the structure of the test protein by literally "threading" each amino acid in the test sequence through proteins in the PDB with similar motifs and folding patterns. Because the total number of folds in nature is fairy small (around 1300), and 90\% of structures submitted to the PDB in the last four years have similar folding patterns, the assumption is made that by using these folding patterns it's possible to determine a rough idea of the structure of the test protein. Because the homology models fell outside of many universally accepted score values, suggesting that a protein like the ACCH Domain had not yet been added to the PDB, threading modeling was vital in determining a final theoretical model.

Homology modeling. The Amot80 amino acid sequence was input into the homology server SWISS-MODEL (http://blast.ncbi.nlm.nih. gov/Blast.cgi). SWISS-MODEL uses sequence identity and coverage percentage to compare the input sequence to similar proteins in the PDB and lists the best matches within the template window (Arnold, Bordoli, Kopp, \& Schwede, 2006; Biasini et al., 2014; Guex, Peitsch, \& Schwede, 2009; Kiefer, Arnold, Künzli, Bordoli, \& Schwede, 2009). Once a template was chosen, the model was built in Coot v0.6.1 using residue replacement, and its global and local quality is quantified using root means square displacement (RMSD) values.

LOMETS thread modeling. The Amot80 sequence was also input into the threading software, LOMETS (Sitao Wu, 2007). LOMETS, a meta-server used for protein prediction, has also been described at length elsewhere (Jaroszewski, Rychlewski, Li, Li, \& Godzik, 2005; Lobley, Sadowski, \& Jones, 2009; Madera, 2008; Söding, 2005; Wu \& Zhang, 2007; D. Xu, Jaroszewski, Li, \& Godzik, 2013; Ying Xu \& Xu, 2000; Yan, Xu, Yang, Walker, \& Zhang, 2013; Zhou \& Zhou, 2004, 2005). In short, LOMETS selects from 200 models generated from associated software and ranks them to find the top 10 models based on the confidence score, or Z-scores. The Z-score is a function of the TM-score and confidence intervals of the individual servers, as well as the sequence identity. The Z-score ranges for good models are generally between 4.0-12.0 (Sitao Wu, 2007). LOMETS reports the rank, template, structural similarity, sequence identity, spatial restraints, Z-score, sequence-ID, and confidence score associated with these top 10 models.

I-TASSER thread modeling. The Amot80 amino acid sequence was input into the threading protein server I-TASSER. I-TASSER has been described at length elsewhere (Roy, Kucukural, \& Zhang, 2010; Yang et al., 2015; Y Zhang, 2008; Yang Zhang, 2008). I-TASSER threading is done by MUSTER, which uses an extended sequence profile-profile alignment algorithm including secondary structure match, fragment structure profile, solvent accessibility, backbone torsion angle, and hydrophobic scoring matrix. A frequency matrix from structurally similar template PDB files is generated leading to the construction of an ab initio full-length model. I-TASSER ranks all models generated based on a confidence score (C-score), which is a combination of RMSD, global fold similarity, and cluster density or frequency of appearance for each template. C-scores generally range from -5 to 2 , where a higher score correlates with higher confidence. The top 5 models are then reported back with their respective structures and confidence scores.

\section{Atomic Model Construction}

Coot modeling suite was used to further refine the top models output from both I-TASSER, LOMETS, and SWISS-MODEL, as well as measure RMSD values for each protein, dimer, and tetramer (Cowtan, 2010). Dimer models were built using the PDB file as a template, and overlaying the final model with the PDB model to check for similarities.

\section{Model Selection}

Models were selected based on template sequence similarity with the Amot80/130 ACCH domain sequence, RMSD between the template PDB coordinates and the suggested model, and redundancy in template selection against the remaining Amot family members. 
Sequence similarity. A phylogeny tree was created using MEGA software comparing the Amot80/130, AmotL1 and AmotL2 ACCH domains with the top 4 threading models and top 3 homology models selected by the respective software scoring function (Tamura K, 2007). For comparison, a representative BAR domain subfamily and PI affinity domain were added to the tree. The software creates a branched tree to show the relationships between the proteins.

Root mean square deviation (RMSD). RMSDs were calculated for each of the top models against the template coordinates deposited into the Protein Database (PDB) using Coot v0.6.1. In general, RMSDs are described as the measurement of divergence between two models when superimposed upon each other and were calculated based on chain alignment of the model against the template.

Ranking and final selection. Models were analyzed from the online threading modeling software SWISS-MODEL, I-TASSER and LOMETS, in addition to a residues replacement model based on the most common template model that occurred across the three software packages. The RMSD and TM-score are listed as

Table 1.

Peptide Spot Blot Amino Acid Sequences

$\begin{array}{rrrr}\text { Spot } & \text { Amino Acid Sequence } & \text { Spot } & \text { Amino Acid Sequence } \\ 0 & \text { MPRAQPSSASYQPVP } & 0 & \text { MPRAQPSSASYQPVP } \\ 1 & \text { AQPSSASYQPVPADP } & 1 & \text { AQPSSASYQPVPADP } \\ 2 & \text { SSASYQPVPADPFAC } & 2 & \text { SSASYQPVPADPFAC } \\ 3 & \text { SYQPVPADPFACIVS } & 3 & \text { SYQPVPADPFACIVS } \\ 4 & \text { PVPADPFACIVSRAQ } & 4 & \text { PVPADPFACIVSRAQ } \\ 5 & \text { ADPFACIVSRAQQMV } & 5 & \text { ADPFACIVSRAQQMV } \\ 6 & \text { FACIVSRAQQMVEIL } & 6 & \text { FACIVSRAQQMVEIL } \\ 7 & \text { IVSRAQQMVEILSDE } & 7 & \text { IVSRAQQMVEILSDE } \\ 8 & \text { RAQQMVEILSDENRN } & 8 & \text { RAQQMVEILSDENRN } \\ 9 & \text { QMVEILSDENRNLRQ } & 9 & \text { QMVEILSDENRNLRQ } \\ 10 & \text { EILSDENRNLRQELE } & 10 & \text { EILSDENRNLRQELE } \\ 11 & \text { SDENRNLRQELEGCY } & 11 & \text { SDENRNLRQELEGCY } \\ 12 & \text { NRNLRQELEGCYEKV } & 12 & \text { NRNLRQELEGCYEKV } \\ 13 & \text { LRQELEGCYEKVARL } & 13 & \text { LRQELEGCYEKVARL } \\ 14 & \text { ELEGCYEKVARLQKV } & 14 & \text { ELEGCYEKVARLQKV } \\ 15 & \text { GCYEKVARLQKVETE } & 15 & \text { GCYEKVARLQKVETE } \\ 16 & \text { EKVARLQKVETEIQR } & 16 & \text { EKVARLQKVETEIQR } \\ 17 & \text { ARLQKVETEIQRVSE } & 17 & \text { ARLQKVETEIQRVSE } \\ 18 & \text { QKVETEIQRVSEAYE } & 18 & \text { QKVETEIQRVSEAYE } \\ 19 & \text { ETEIQRVSEAYENLV } & 19 & \text { ETEIQRVSEAYENLV } \\ 20 & \text { IQRVSEAYENLVKSS } & 20 & \text { IQRVSEAYENLVKSS } \\ 21 & \text { VSEAYENLVKSSSKR } & 21 & \text { VSEAYENLVKSSSKR } \\ 22 & \text { AYENLVKSSSKREAL } & 22 & \text { AYENLVKSSSKREAL } \\ 23 & \text { NLVKSSSKREALEKA } & 23 & \text { NLVKSSSKREALEKA } \\ 24 & \text { KSSSKREALEKAMRN } & 24 & \text { KSSSKREALEKAMRN } \\ 25 & \text { SKREALEKAMRNKLE } & 25 & \text { SKREALEKAMRNKLE } \\ 26 & \text { EALEKAMRNKLEGEI } & 26 & \text { EALEKAMRNKLEGEI } \\ 27 & \text { EKAMRNKLEGEIRRM } & 27 & \text { EKAMRNKLEGEIRRM } \\ 28 & \text { MRNKLEGEIRRMHDF } & 28 & \text { MRNKLEGEIRRMHDF } \\ 29 & \text { KLEGEIRRMHDFNRD } & 29 & \text { KLEGEIRRMHDFNRD } \\ 30 & \text { GEIRRMHDFNRDLRE } & 30 & \text { GEIRRMHDFNRDLRE } \\ 31 & \text { RRMHDFNRDLRERLE } & 31 & \text { RRMHDFNRDLRERLE } \\ 32 & \text { HDFNRDLRERLETAN } & 32 & \text { HDFNRDLRERLETAN } \\ 33 & \text { NRDLRERLETANKQL } & 33 & \text { NRDLRERLETANKQL } \\ 34 & \text { LRERLETANKQLAEK } & 34 & \text { LRERLETANKQLAEK } \\ 35 & \text { RLETANKQLAEKEYE } & 35 & \text { RLETANKQLAEKEYE } \\ 36 & \text { TANKQLAEKEYEGSE } & 36 & \text { TANKQLAEKEYEGSE } \\ 37 & \text { KQLAEKEYEGSEDTR } & 37 & \text { KQLAEKEYEGSEDTR } \\ 38 & \text { AEKEYEGSEDTRKTI } & 38 & \text { AEKEYEGSEDTRKTI } \\ 39 & \text { EYEGSEDTRKTISQL } & & \\ & & & \end{array}$

a means of comparing between software packages. A TM-score between 0 and 0.17 typically corresponds to random structural similarity, while TM-scores $>0.5$ typically corresponds to a higher propensity for the structure to be similar to the structural folds of the template and previously reported in the SCOP/CATH database citation (J. Xu \& Zhang, 2010; Y. Zhang \& Skolnick, 2004, 2007).

\section{EXPERIMENTAL RESULTS Identifying Lipid Affinity Residues}

Being classified as a membrane protein, Amot is known to associate and bind with lipid. To determine the region(s) of the ACCH domain responsible for this lipid binding, SPOTs immobilized peptide arrays were used to determine both domain regions and individual residues with lipid affinity. The first assay, the peptide tiling array spot blot, utilized peptides from the overall protein sequence to determine domain regions that may drive lipid binding. The second assay, the mutant protein spot blot, utilized a similar design where the entire protein with very specific point mutations was used to determine the role of individual amino acids within the context of the entire domain.

Peptide tiling array spot blot. An array of overlapping peptides was used to experimentally determine regions of the protein that may do this targeting function. A total of 76 peptides (Table 1) were constructed as previously described, where peptides are 15 amino acids in length and each peptide in the tile is shifted by three amino acids (Ashpole \& Hudmon, 2011). This method benefits from each residue being within several peptides, to allow the characterization of each residue's affinity contribution. This method found five distinct peptide regions where there was at least 50\% liposome binding when compared to the entire domain (Figure 2). Based on the characteristics of the liposome, which can be described as negatively charged PI4P head groups incorporated into an aliphatic "sphere," peptide affinity may be driven by charge and hydrophobicity. Hence, the charge and hydrophobicity of each

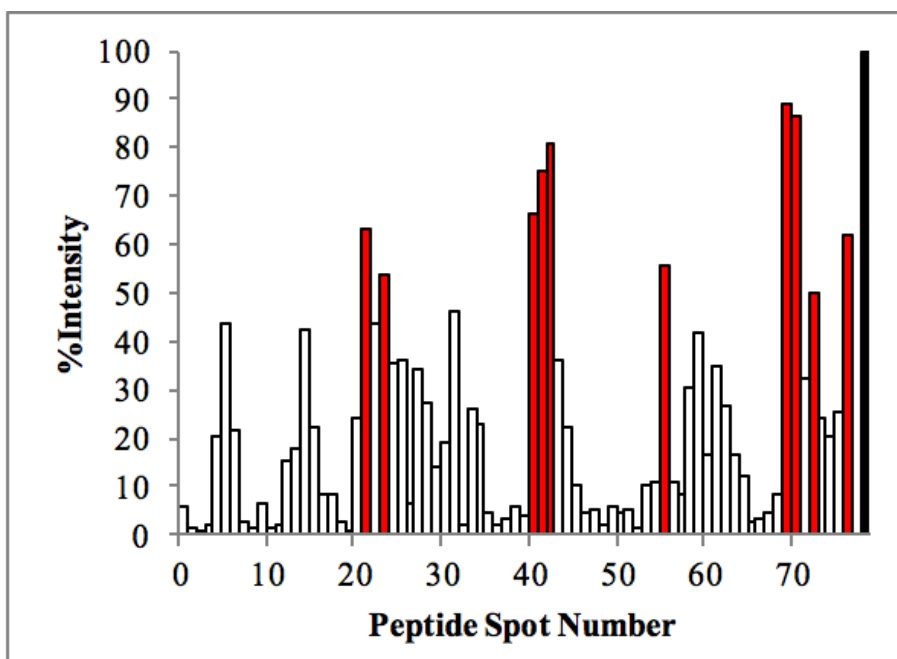

Figure 2.

Amot80 ACCH domain peptide spot blot array. Fluorescence intensity of each peptide spot from the immobilized peptide array of the Amot80/130 ACCH domain as quantified by Odyssey v1.2. Peptide affinity is compared against $3.9 \mu M$ protein. The characteristics of each peptide with over $50 \%$ lipid affinity are listed in Table 2. 
Table 2.

Characterization of Specific Peptides from Figure 2

\begin{tabular}{|c|c|c|c|c|c|c|}
\hline Spot & $\begin{array}{l}\text { \% Intensity in } \\
\text { SPOTs Assay }\end{array}$ & $\begin{array}{l}\text { Targeted Amot80 } \\
\text { Residues }\end{array}$ & $\begin{array}{l}\text { Net Charge at } \\
\text { pH } 7\end{array}$ & Basic residues & $\begin{array}{l}\text { Hydrophobicity } \\
\text { at pH } 6.8\end{array}$ & $\begin{array}{l}\text { Tyrosine } \\
\text { Residues }\end{array}$ \\
\hline 5 & 44.0 & $16-30$ & -0.09 & $\mathrm{R} 25$ & 30.27 & \\
\hline 14 & 42.6 & $43-57$ & -0.09 & K50, R53, K56 & 22.8 & Y48 \\
\hline 21 & 62.9 & $64-78$ & 1 & $\mathrm{~K} 73, \mathrm{~K} 77, \mathrm{R} 78$ & 11.53 & Y68 \\
\hline 23 & 53.9 & $70-84$ & 2 & $\mathrm{~K} 73, \mathrm{~K} 77, \mathrm{R} 78, \mathrm{~K} 83$ & 10.47 & \\
\hline 42 & 80.8 & $127-141$ & 3 & K127, K135, K137, R141 & 11 & \\
\hline 55 & 55.8 & $166-180$ & 2 & $\mathrm{R} 167, \mathrm{~K} 176, \mathrm{~K} 180$ & 19.53 & \\
\hline 69 & 88.8 & $208-222$ & 2.02 & K213, R214, 220, R222 & 8.67 & \\
\hline 76 & 62.1 & $229-243$ & 1.91 & R231, R235 & 4 & \\
\hline
\end{tabular}
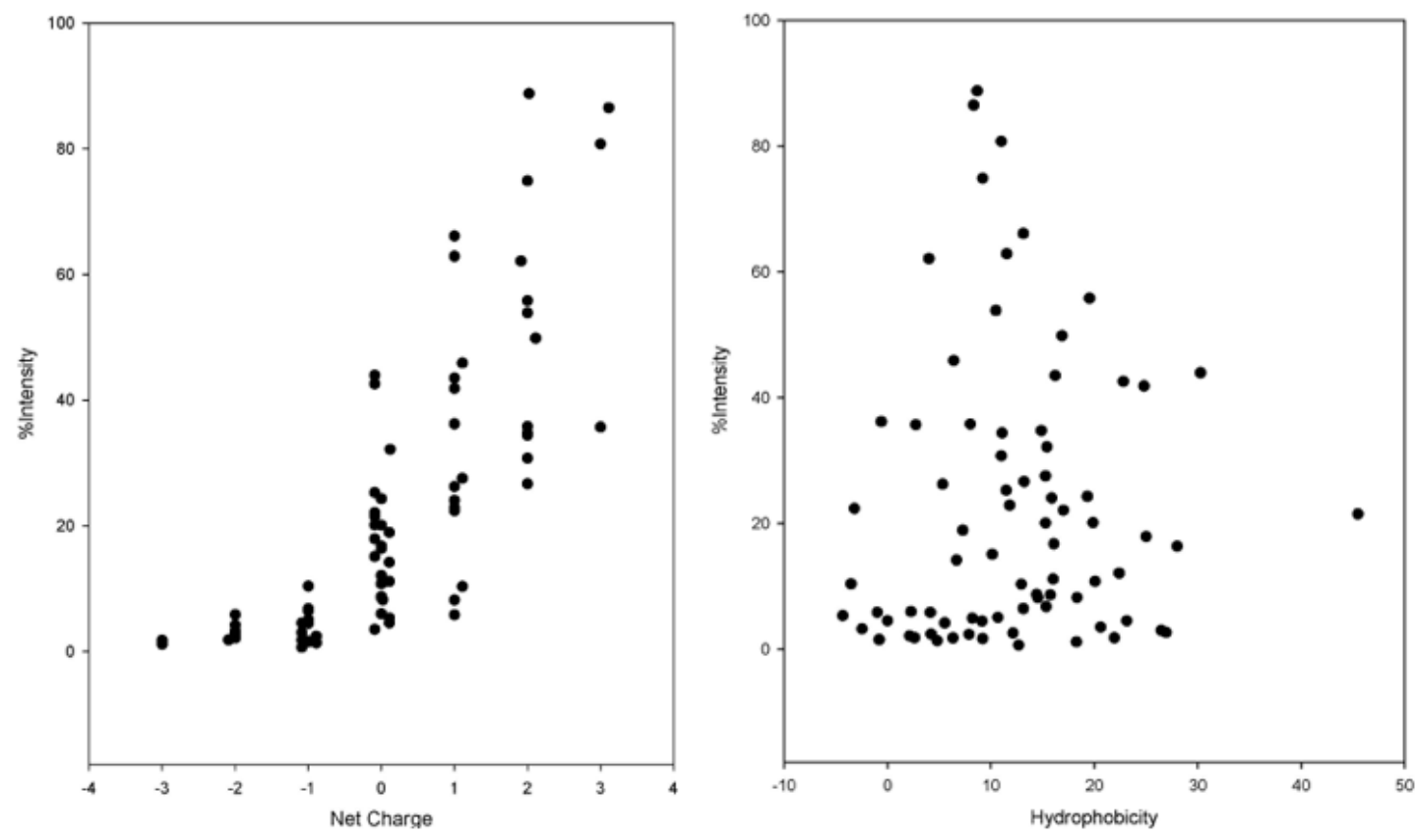

Figure 3.

General characterization of all peptides in spot array. This figure shows the characterization of peptides in Figure 2/Table 1 for their net charge and hydrophobicity using a peptide property calculator (LifeTein).

peptide was calculated using a peptide property calculator and described graphically in Figure 3. The general trend indicated that a positive increase in charge leads to a greater liposome affinity However the cluster of positively charged residues in Figure 3 (left) shows an affinity between $40-100 \%$ affinity which is a large enough range to suggest that charge is not totally driving the affinity of the peptides. Consideration was also given to the role of hydrophobicity in peptide affinity, however the data cluster in Figure 3 (right) suggests that hydrophobicity is probably not the driving force for liposome affinity. While this analysis does not take into account the effect of both charge and hydrophobicity, nor the order of the amino acids presented, it can be assumed that the entire sequence as presented drives the high affinity of the peptides listed in Table 2. It has been reported that charged residues drive interaction of peptides with the exterior of a membrane bilayer while tyrosine and tryptophan drive interaction with the head group region of the membrane (Senes et al., 2007). Additionally, other PI affinity domains such as $\mathrm{PH}$ and FYVE domains have basic pockets or a positively charged region of the domain to drive affinity PI lipid head groups (Rong et al., 2001; Harald Stenmark et al., 1996; Y Xu et al., 2001). The ACCH domain does not contain any tryptophan residues; however, the tyrosine and basic residues that may drive lipid affinity in each peptide have been highlighted in Table 2.

Specificity of peptide affinity. To further distinguish the effect of charge and hydrophobicity on peptide affinity for PI4P containing vesicles, three peptides from the C-terminus of the protein sequence were chosen for further analysis. The peptides designed for this experiment selectively targeted lysine and arginine residues and their compliment that changed them to an alanine. Table 3 lists each of the peptide sequences that generated and blotted in this experiment.

Mutational analysis. Further investigation into the regions of the ACCH domain that may participate in lipid binding was done by mutational analysis in a GST fusion construct of the entire domain. All of the suggested residues were mutated using site 
Table 3.

Peptide Sequences for Arg/Lys Selectivity Spot Blot Experiment

\begin{tabular}{c|c|c}
\hline \multirow{2}{*}{ Spot } & & Amino Acid Sequence \\
\hline A & \multirow{2}{*}{ Wild Type } & EAELATARSTNEDQ \\
\cline { 1 - 1 } B & & EAELATARSTNEDQ \\
\hline C & Mutant & EAELATAASTNEDQ \\
\hline D & \multirow{2}{*}{ Wild Type } & AAQAKVVKLEEEL \\
\cline { 1 - 1 } E & & AAQAAVVKLEEEL \\
\hline F & Mutant & AAQAAVVALEEEL \\
\hline G & \multirow{2}{*}{ Wild Type } & EQLEHRLRTRLEREL \\
\cline { 1 - 1 } H & & EQLEHRLATRLEREL \\
\hline I & Mutant & EQLEHALATALEAEL \\
\hline
\end{tabular}

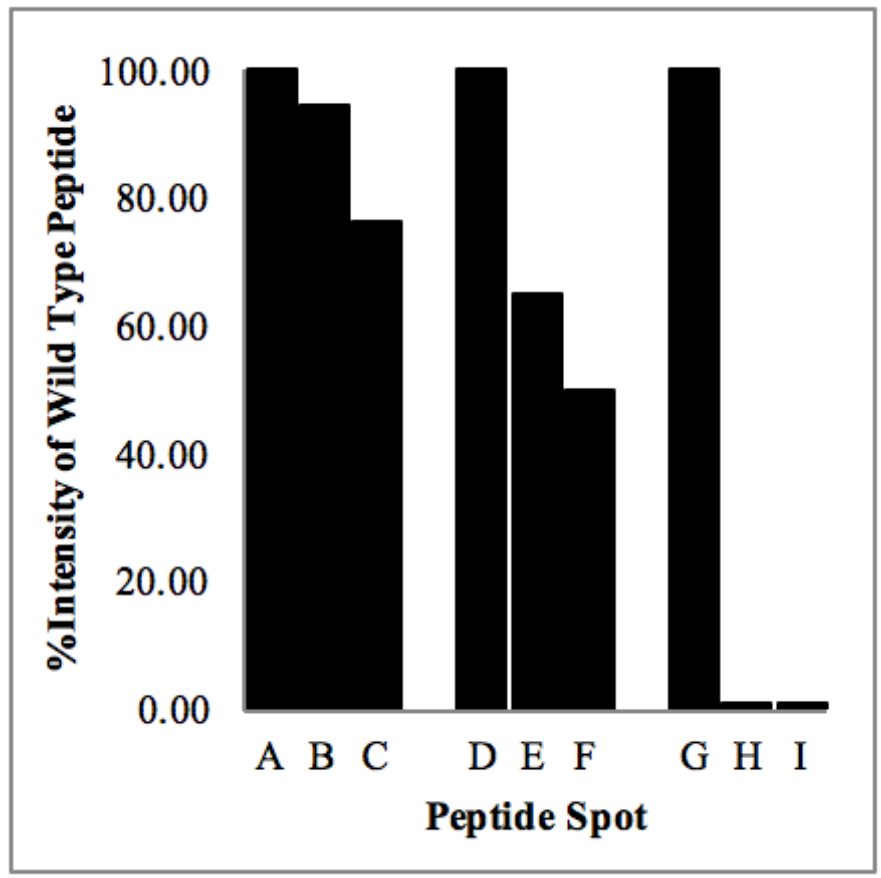

Figure 4.

Peptide spot blot affinity for liposomes as a function of Arg/ Lys content. Fluorescence intensity of each peptide spot from the immobilized peptide array of the Amot80/130 ACCH domain as quantified by Odyssey $v 1.2$, and reported as a percentage of the wild type peptide sequence. This figure compares the designed peptides against their wild type sequence when selected Arg/Lys residues are changed to Ala as listed in Table 3.

directed mutagenesis for making purified protein. Each mutation was screened using a previously described lipid sedimentation assay (Heller et al., 2010) where $20 \mu \mathrm{M}$ protein and $15 \mathrm{mM}$ POPC/ POPE/soy PI (60/20/20 mol\%) are incubated, centrifuged, and then characterized for the amount of protein associated with the supernatant and lipid pellet. In these experiments, mutations to the following residues resulted in greater than $40 \%$ loss in lipid binding: Lys50, Arg53, Tyr68, Lys83, Lys180, and Arg220 (data not shown). Each mutation was then tested for significant loss in lipid binding affinity using the protein spot blot assay against POPC/POPE/Chol/PI4P liposomes. The lipid binding isotherm for the wild type protein and Lys83 are shown in Figure 6 as a representative of the data collected using this assay. Those mutations having a change in their lipid binding constant have been reported in Table 4, with the greatest loss of binding seen for Lys83 and Lys180. The collection of this data suggests that these two residues participate in active binding, while the highly charged and hydrophobic nature of the c-terminus of the domain maintains that association.

\section{SAXS Based Model of the ACCH Domain}

After determining the regions of the protein that participate in lipid association events, we endeavored to use SAXS to determine where these residues reside within the structure of the protein. The globular shape of the Amot80/130 ACCH domain was then investigated using SAXS data.

Guinier analysis. The experimental data of the ACCH domain at $1.4 \mathrm{~g} / \mathrm{L}$ is shown in Figure 7. The low-q region of the scattering data obtained showed a linear correlation and was to make a Guinier plot (Figure 8). The radius of gyration $\left(\mathrm{R}_{\mathrm{g}}\right)$ determined from this plot was used to postulate either the radius of a sphere or the length of a cylindrical rod. Additionally, the intermediate-q region of the scattering data was used to plot the second dimension $\mathrm{R}_{\mathrm{g}}$ for the cylindrical rod (Figure 9). When modeling the protein as a sphere, the $\mathrm{R}_{\mathrm{s}}$ was determined to be $\sim 188.3 \AA$ which calculates to a spherical radius of $\sim 19.4$ $\AA$ (Table 5). When modeling the protein as a cylindrical rod, the intermediate- $\mathrm{q} \mathrm{R}_{\mathrm{g}}$ was determined to be $\sim 12.01 \AA$ which calculates to a cylindrical radius of $\sim 16.99 \AA$ and a length of $\sim 651$ $\AA$ (Table 5). The computed $\mathrm{R}_{\mathrm{g}}$ was similar to those calculated using GNOM (Table 5). The results suggest that the protein could be modeled using either a spherical or rod globular envelope. However, when compared to the broad selection of theoretical models generated it suggests that this protein most likely has a rod-like structure.

\section{THEORETICAL RESULTS Secondary Structure}

COILS2 and Clustal Omega were used to predict secondary structure with the goal of determining which regions of the ACCH domain are helical and random coil. (Lupas, 1991; Sievers F, 2011). Figure 10 is the result of the Amot80/130 ACCH domain sequence being input into COILS2. It reports the probability of a residue forming a coiled-coil. To alleviate bias towards hydrophilic, charge rich sequences, COILS2 allows the user to assign the same weight to the two hydrophobic positions (a,d) as the five hydrophilic positions (b,c,e,f,g). Both an unweighted and a weighted scan were performed and yielded extremely similar results, so the unweighted results were used. Clustal Omega was used to predict secondary structure and then align predicted structure regions from 6 different software packages, including I-TASSER, Psipred, LOMETS, DSC, REMARK, and CFSSP (Buchan DWA, 2013). Figure 11 shows the Amot80 sequence highlighted in black, and the coil/helix predictions. In this figure, Clustal Omega suggests that the majority of this domain forms either a random coil (C) or alpha helix (H). Unanimously predicted random coil regions residues are colored orange, and unanimously predicted 

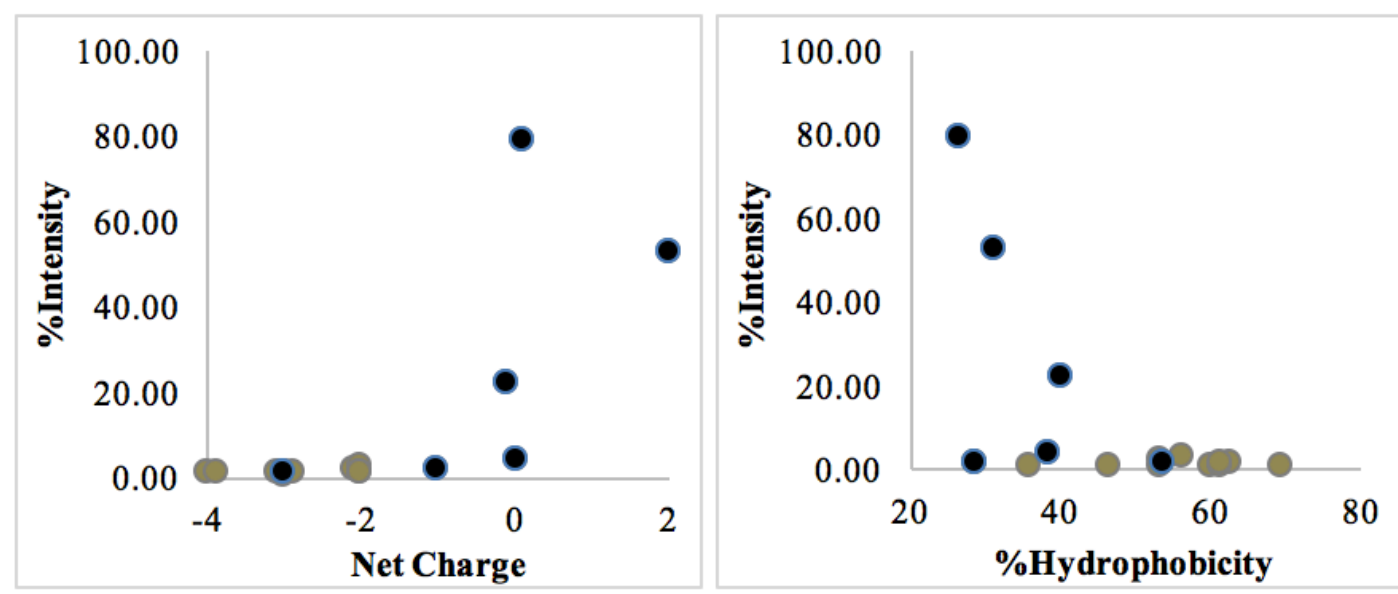

Figure 5.

General characterization of the peptides from the Arg/Lys selectivity spot blots experiment. We characterized the peptides in Figure 4/Table 3 for their net charge and hydrophobicity using a peptide property calculator (LifeTein).

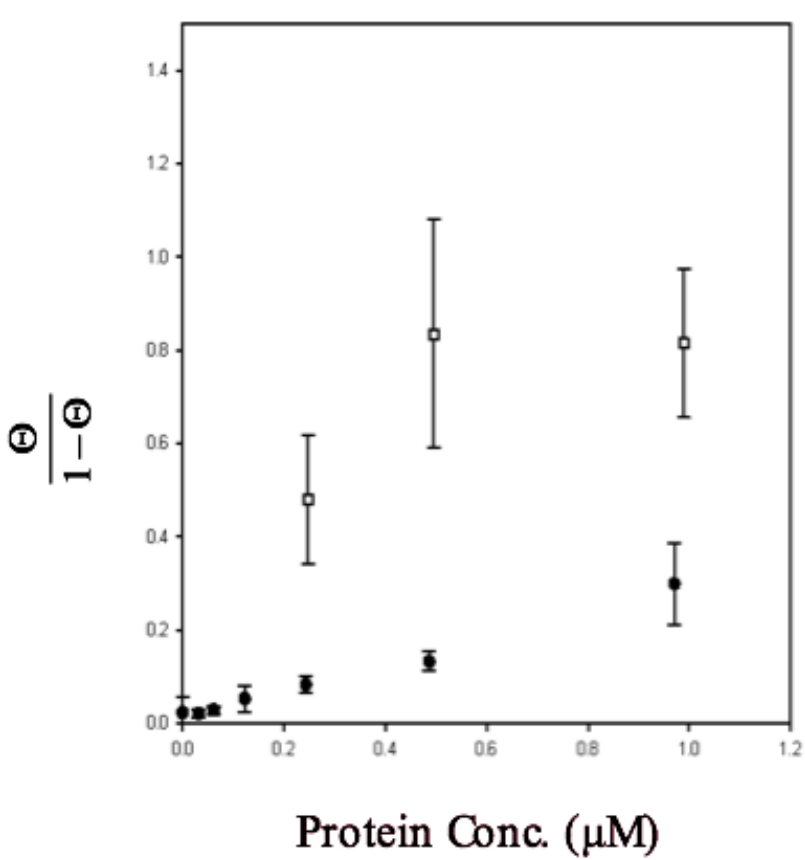

Figure 6.

Lipid affinity by ACCH domain determined by protein spot blot array. Example fractions of the lipid bound to purified wild type protein ( $\square$ ) versus mutant $K 83 E(\bullet)$ as a function of protein concentration (n-5, \pm S.D.). The binding constants are reported in Table 4.

Table 4.

Mutations Leading to Changes in Lipid Affinity as Measured by Protein Spot Blotting

\begin{tabular}{cccc} 
Mutation & $\mathbf{K}_{\mathbf{L}}\left(\boldsymbol{\mu \mathbf { M } ^ { - 1 } )}\right.$ & Std. Error & Fold Change \\
Wild Type & 0.06 & 0.003 & \\
Y48F & 0.19 & 0.01 & 3 \\
R53G & 0.32 & 0.02 & 5 \\
Y68F & 0.15 & 0.01 & 3 \\
K83E & 0.28 & 0.02 & 5 \\
K180E & 0.80 & 0.04 & 13 \\
\hline
\end{tabular}

helical regions residues are colored blue. In general, all of the software packages predict similarly where most of the domain is alpha helical in nature with small random coil regions on each end. These results are similar to those previously reported about the Amot family of proteins (Heller et al., 2010). In short, we determined from the secondary software programs listed that the ACCH domain contains almost entirely random coil (C) or alpha helix $(\mathrm{H})$.

\section{Homology Models}

After confirming the ACCH domain's coiled-coil and helical character, SWISS-MODEL and BLAST were used to predict 3 -D structure by comparing the test protein to other proteins in the PDB using protein homology. No structural information for Angiomotin is currently available on any of these databases. Proteins are analyzed based on sequence identity as well as polarity, hydrophobicity, and acidity. A BLAST search of nonredundant protein database yielded the DUF342 superfamily. A PSI-BLAST run of the same sequence within the SWISS-MODEL database yielded NUDEL, Rho-associated protein kinase, and most prevalently, actin/myosin subunits. SWISS-MODEL was also used to generate homology models for all 3 Amot family members. The models were then ranked based on Global Model Quality Estimation (GMQE), where models are scored on a scale of $0-1$ with higher scores indicates a higher reliability. Table 6 reports the statistical analysis of the top congruent models generated for all Amot family members. This analysis suggests that all of the models generated were suitable templates (Table 6 \&Table 7). The models can be clustered into 3 categories based on which template structures were used: HP0958 (ModelS17), dimeric NUDEL (ModelS09, ModelS10), and tetrameric NUDEL (ModelS07, ModelS08, ModelS06). NUDEL homology models generated from the same template have similar statistics, suggesting that they could be jointly incorporated into a singular dimeric or tetrameric model. Figure 12 is a pictorial representation of the coiled coil ModelS17 (Figure 12A), dimer of simple helix ModelS09 and ModelS10 (Figure 12B), tetramer of ModelS09 and ModelS10 (C) where the models were aligned to PDB ID 2V66, and a tetramer of simple helices from ModelS05-7 (Figure 12D). 


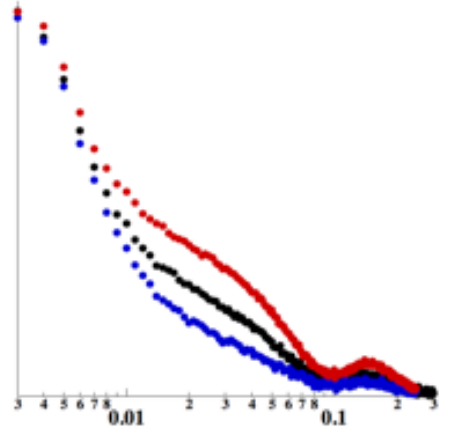

Figure 7.

SAXS and WAXS of Amot80/130 ACCH domain at $0.7 \mathrm{~g} / \mathrm{L}$. SAXS and WAXS intensity profiles of $0.3(\bullet), 0.7(\bullet)$, and 1.4 (•) $\mathrm{g} / \mathrm{L}$ protein, where the background signal has been subtracted.

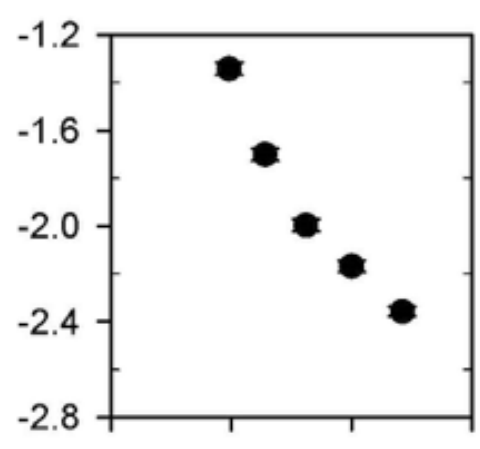

Figure 8.

Guinier plot of low q. The Guinier fits for the low q linear region of the $0.7 \mathrm{~g} / \mathrm{L}$ SAXS data from Figure 7. The slope of the line was used to estimate the radius of gyration and either the radius of the protein when modeled as a sphere or the length when modeled as a cylinder.

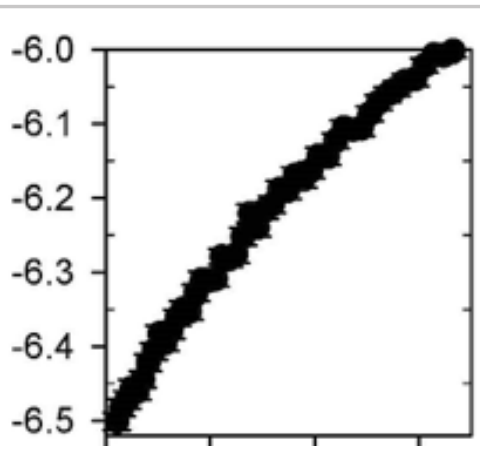

Figure 9.

Guinier plot of rod intermediate q. The long rod/cylinder Guinier fits for the intermediate $q$ linear region of the $0.7 \mathrm{~g} / \mathrm{L}$ SAXS data from Figure 7 . The slope of the line was used to estimate the radius of gyration and the radius of the protein when modeled as a rod.

Table 5.

Guinier Analysis of SAXS Data

\begin{tabular}{|c|c|c|c|c|c|c|c|c|c|}
\hline \multirow[b]{2}{*}{ Sphere } & \multirow{2}{*}{$\begin{array}{c}\text { Low-q } \mathbf{R}_{\mathbf{q}}(\AA) \\
188.31\end{array}$} & \multicolumn{2}{|c|}{ Dimension (Å) } & $\mathbf{R}^{2}$ & Int-q $R_{g}(\AA)$ & \multicolumn{2}{|c|}{ Dimension (Å) } & $\mathbf{R}^{2}$ & \multirow{2}{*}{$\begin{array}{c}\text { GNOM Rg }(\AA) \\
174.21 \\
\pm 0.066\end{array}$} \\
\hline & & Radius & $\begin{array}{c}19.4 \\
\pm 0.8\end{array}$ & & \multicolumn{4}{|c|}{$\mathrm{N} / \mathrm{A}$} & \\
\hline $\begin{array}{l}\text { Rod/long } \\
\text { cylinder }\end{array}$ & & Length & $\begin{array}{l}65 \\
\pm 2\end{array}$ & 0.9413 & 12.01 & Radius & $\begin{array}{l}16.98 \\
\pm 0.04\end{array}$ & 0.9816 & $\begin{array}{c}18.21 \\
\pm 0.005\end{array}$ \\
\hline
\end{tabular}

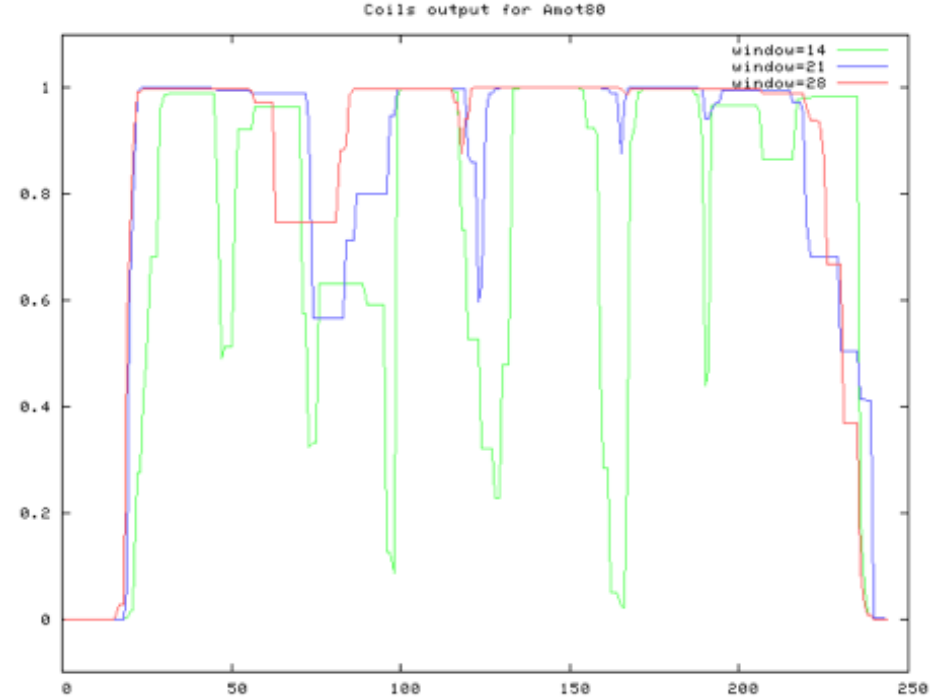

Figure 10.

COILS secondary structure prediction. COILS2 coiled-coil analysis using the MTK matrix with $2.5 x$ fold weighting of positions a,d. Probability of coiled-coil is shown on the $y$-axis out of 1 and residue number is shown on the $x$-axis for the protein.

\section{LOMETS Threading Models}

To complement the homology models discussed previously, we used LOMETS to generate 10 threading models without restraints. Similar to homology modeling, threading software selects templates from the pdb that are structurally similar to the test protein. However, instead of comparing the test protein to the pdb protein directly, threading software feeds each amino acid of the test protein through the template and determines how well it fits in relation to the pdb model. As a result, we have the following top threads: the coiled coil region in tropomyosin (PDB ID 2TMA), a contractile protein; the coiled-coil region of Atg17/31/19 complex (PDB ID 4HPQ), a protein transport scaffold; the HBL Domain of NheA (PDB ID 4K1P), a bacterial toxin; the coiled-coil region in PcsB (PDB ID 4CGK), a cell cycle modulator, the protein TcdA1 (PDB ID 4O9Y), a toxin; spermine induced coiled-coil region tropomyosin (PDB ID $1 \mathrm{C} 1 \mathrm{G}$ ), a contractile protein; DHR64 (PDB ID 5CWM), a helical repeat de novo protein expressed in E. Coli; and a computationally designed three-helix bundle (PDB ID 4TQL). The templates were then ranked based on TM-Score, where we removed models from the list with a score less than 0.17 (cutoff for random assignment) resulting in five meaningful models generated (Table 8). Using the amino acid sequence for AmotL1 and AmotL2, the other two Amot family members, LOMETS generated models using four of the same templates as seen for Amot80. This further informed 


\begin{tabular}{|c|c|}
\hline & 60 \\
\hline Amot 80 & MPRAOPSSASYOPVPADPFACIVSRAOOMVEILSDENRNLROELEGCYEKVARLOKVETE \\
\hline ITASSER & 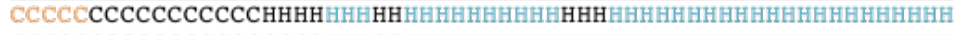 \\
\hline Psipred & 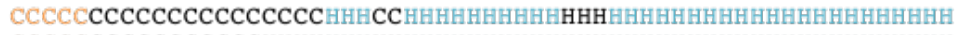 \\
\hline LOMETS & 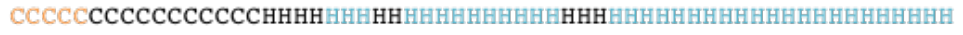 \\
\hline DSC & 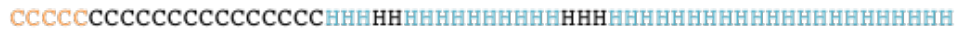 \\
\hline REMARK & 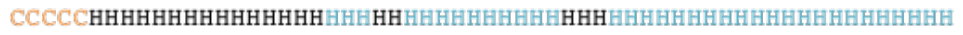 \\
\hline \multirow[t]{2}{*}{ CFSSP } & 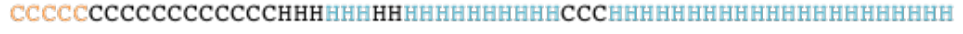 \\
\hline & 120 \\
\hline Amot 80 & IORVSEAYENLVKSSSKREALEKAMRNKLEGE IRRMHDFNRDLRERLETANKOLAEKEYE \\
\hline TASSER & 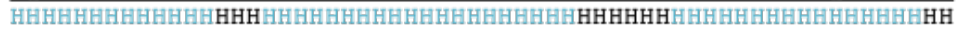 \\
\hline psipred & 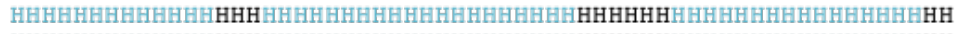 \\
\hline LOMETS & 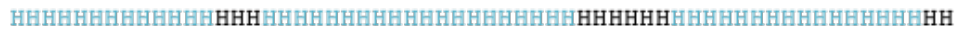 \\
\hline DSC & 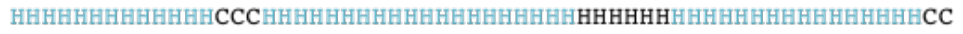 \\
\hline REMARK & 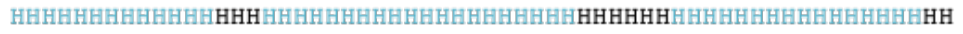 \\
\hline \multirow[t]{2}{*}{ CFSSP } & 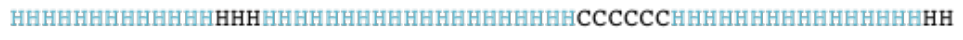 \\
\hline & 121 \\
\hline Amot 80 & GSEDTRKTISOLFAKNKESOREKEKLEAELATARSTNEDQRRHIEIRDOALSNAOAKVVK \\
\hline ITASSER & 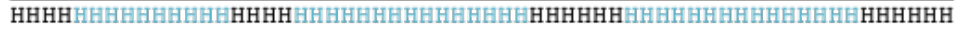 \\
\hline psipred & 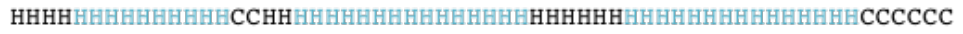 \\
\hline LOMETS & 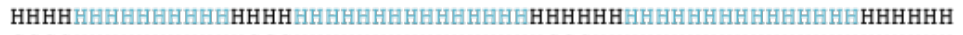 \\
\hline DSC & 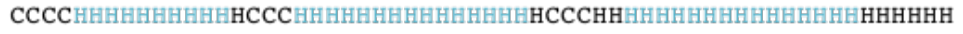 \\
\hline REMARK & 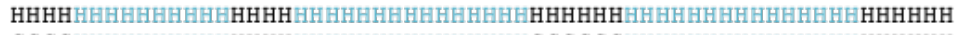 \\
\hline \multirow[t]{2}{*}{ CFSSP } & 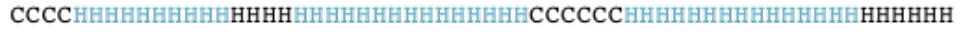 \\
\hline & $181 \quad 240$ \\
\hline Amot 80 & LEEELKKKOVYVDKVEKMOOALVQLOAACEKREOLEHRLRTRLERELESLRIOQROGNCO \\
\hline ITASSER & 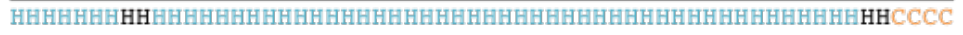 \\
\hline psipred & 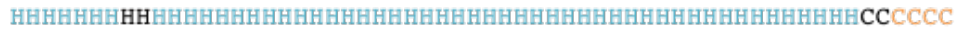 \\
\hline LOMETS & 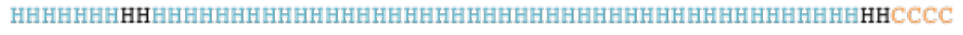 \\
\hline DSC & НHНHНHНCC \\
\hline REMARK & 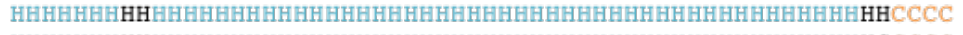 \\
\hline \multirow[t]{2}{*}{ CFSSP } & 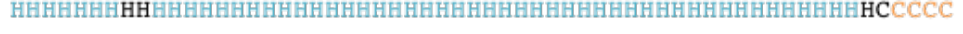 \\
\hline & 245 \\
\hline Amot 80 & PTNVS \\
\hline ITASSER & $\operatorname{ccccc}$ \\
\hline psipred & $\operatorname{ccccc}$ \\
\hline LOMETS & $\operatorname{ccccc}$ \\
\hline DSC & $\operatorname{ccccc}$ \\
\hline REMARK & $\operatorname{ccccc}$ \\
\hline CFSSP & $\mathrm{CCCCC}$ \\
\hline \multicolumn{2}{|c|}{ Figure 11.} \\
\hline \multicolumn{2}{|c|}{$\begin{array}{l}\text { Clustal Omega sequence alignment of secondary structure. Clustal Omega coil/helix } \\
\text { compilation of } 6 \text { separate modeling software. The top line highlighted in black in the Amot80 } \\
\text { sequence, C represents coil, and H represents helix. Universally predicated coil regions are } \\
\text { colored orange, universally helical regions are colored blue, and all other predictions are black. }\end{array}$} \\
\hline
\end{tabular}

the use of ModelT01, ModelT02, ModelT04 and ModelT08. Based on the criteria that the best models have Z-scores between 4-12 for all models presented, ModelT01 was the best model generated followed by ModelT04 (Table 8).

\section{I-TASSER Threading Models}

In addition to LOMETS, we also utilized I-TASSER to generate 10 threading models without restraints. Based on C-score, the following proteins are our top threads: DHR64 (PDB ID 5CWM), a helical repeat de novo protein expressed in E. Coli; the coiled coil region in tropomyosin (PDB ID 2TMA), a contractile protein; the VRP1 domain of the protein TcdA1 (PDB ID 4O9Y), a toxin; the coiled-coil region in fibrinogen (PDB ID 1DEQ), a blood clotting protein; spermine induced coiled-coil region tropomyosin (PDB ID $1 \mathrm{C} 1 \mathrm{G}$ ), a contractile protein; the coiledcoil region in $\mathrm{PcsB}$ (PDB ID 4CGK), a cell cycle modulator; the coiled-coil region of Atg17/31/19 complex (PDB ID 4HPQ), a protein transport scaffold; the HBL Domain of NheA (PDB ID 4K1P), a bacterial toxin; and the coiled-coil NUDEL protein (PDB ID 2V71), a nuclear protein involved in cell division. We then ranked the templates based on TM-Score, and removed from the list models with a score less than 0.17 (cutoff for random assignment), resulting in five meaningful models generated from I-TASSER (Table 9). Again, we used the AmotL1 and AmotL2 sequences to verify the models previously mentioned. Based on the criteria that the best models have C-scores between -5 and 2, where higher scores are indicative of being better fits. As a result, this software confirmed ModelT07, ModelT10 and ModelT11 as probable models. Although

Table 6.

Top Homology Models Across Amot family Built by SWISS-MODEL

\begin{tabular}{|c|c|c|c|c|c|c|c|}
\hline \multirow{2}{*}{ Model } & \multirow{2}{*}{$\begin{array}{l}\text { Protein } \\
\text { Template } \\
\text { (PDB ID) }\end{array}$} & \multirow{2}{*}{$\begin{array}{l}\text { \% Seq. } \\
\text { Identity }\end{array}$} & \multirow{2}{*}{ RMSD } & \multicolumn{3}{|c|}{ GMQE } & \multirow{2}{*}{ TM-Score } \\
\hline & & & & Amot80 & AmotL1 & AmotL2 & \\
\hline ModelS17 & $\begin{array}{c}\text { HP0958 } \\
\text { (3na7.1.A) }\end{array}$ & 13.45 & 44.88 & 0.42 & 0.39 & 0.40 & 0.227 \\
\hline Model S09 & $\begin{array}{c}\text { NUDEL } \\
\text { (2V71.1.A) }\end{array}$ & \multirow{2}{*}{21.90} & 7.32 & 0.33 & 0.18 & 0.32 & 0.296 \\
\hline Model S10 & $\begin{array}{c}\text { NUDEL } \\
\text { (2V71.1.B) }\end{array}$ & & 7.21 & 0.33 & N.D.* & 0.32 & 0.264 \\
\hline Model S07 & $\begin{array}{c}\text { NUDEL } \\
\text { (2V66.1.C) }\end{array}$ & \multirow{4}{*}{25.51} & 6.17 & 0.24 & 0.22 & 0.14 & 0.313 \\
\hline Model S08 & $\begin{array}{c}\text { NUDEL } \\
(2 \mathrm{~V} 66.1 . \mathrm{B})\end{array}$ & & 6.60 & 0.24 & 0.22 & 0.14 & 0.322 \\
\hline Model S06 & $\begin{array}{c}\text { NUDEL } \\
\text { (2V66.1.D) }\end{array}$ & & 6.62 & 0.23 & 0.22 & 0.14 & 0.294 \\
\hline Model S05 & $\begin{array}{c}\text { NUDEL } \\
\text { (2V66.1.E) }\end{array}$ & & 6.423 & 0.23 & 0.22 & 0.15 & 0.2988 \\
\hline
\end{tabular}


ModelT03 did not have models generated for AmotL1 and AmotL2, it is significant that the template is related to the other tropomyosin template ModelT11. Based on the combination of TM-Score and C-score, three models were carried forward for further analysis: coiled-coil ModelT07, coiled coil ModelT10, and simple helix ModelT11.

\section{Structural Comparison of Generated Models}

After determining the best models from both software, we compared them to determine the best template to use for SAXS modeling. Many of the threads overlap because LOMETS functions as a broader server, while I-TASSER focuses on further refining the LOMETS models. Furthermore, SWISS MODEL generated similar models based on the same template as threading model ModelT01. Figure 13 shows an alignment of the simple helix models ModelT01, ModelT02, and ModelT03. This figure highlights the similarities and differences between the three models. All three models are single helices, and have a rolling structure with two distinct rise and falls around $1 / 3$ and $2 / 3$ into the model. The primary differences lie in the height of the rise. Interestingly, the tropoyosin models stemming from LOMETS and I-TASSER were different despite using the same thread. Figure 14 shows a coiled coil model based on Myosin-V. In general, the coiled coil models generated from both the homology and threading software were so structurally dissimilar that they could not be aligned in the same manner as the simple helix models.

\section{Phylogeny Tree}

To compare and check the relevancy of all the models generated, the template sequences were analyzed for sequence similarity using MEGA (Tamura, Stecher, Peterson, Filipski, \& Kumar, 2013) and aligned with ClustalW (Goujon et al., 2010; Sievers et al., 2011). For comparison, AmotL1 and AmotL2 were also included, as the Amot80/130 ACCH domain shares over 68\% (80\% conservation) and $56 \%$ identity (70\% conservation). As the $\mathrm{ACCH}$ domain has been described as a BAR domain in other sources (Heller et al., 2010), one of each type of BAR domains were also compared to the ACCH domain sequence. The results of those comparisons were combined into the phylogeny tree seen in Figure 15. Proteins that are close relatives are proximal to each other, while further distances suggest a weaker relationship. Based on the sequence identities, the closest relatives to the Amot

Table 7.

Oligomeric Forms of SWISS-MODELs from Table 6

\begin{tabular}{c|c|c|c|c}
\hline & Model & $\begin{array}{c}\text { SWISS-MODEL } \\
\text { Template(s) }\end{array}$ & RMSD & TM-Score \\
\hline \multirow{2}{*}{$\begin{array}{c}\text { Tetramer } \\
\text { aligned to } \\
\text { PDB ID 2V66 }\end{array}$} & ModelS20 & ModelS09, ModelS10 & 7.22 & 0.2948 \\
\cline { 2 - 5 } & ModelS22 & ModelS10 & 7.273 & 0.2713 \\
\cline { 2 - 5 } & ModelS26 & $\begin{array}{c}\text { ModelS05, ModelS06, } \\
\text { ModelS07, ModelS08 }\end{array}$ & 6.603 & 0.2948 \\
\hline \multirow{2}{*}{$\begin{array}{c}\text { aligned to } \\
\text { PDB ID 2V71 }\end{array}$} & ModelS24 & ModelS09, ModelS10 & 7.316 & 0.3221 \\
\cline { 2 - 5 } & ModelS25 & ModelS10 & 7.121 & 0.2769 \\
\hline
\end{tabular}

A)

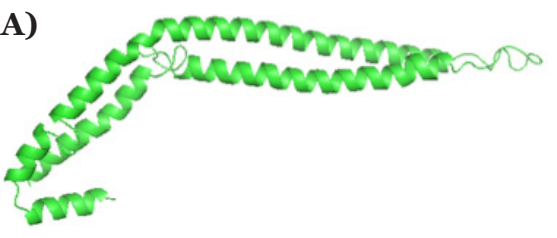

B)
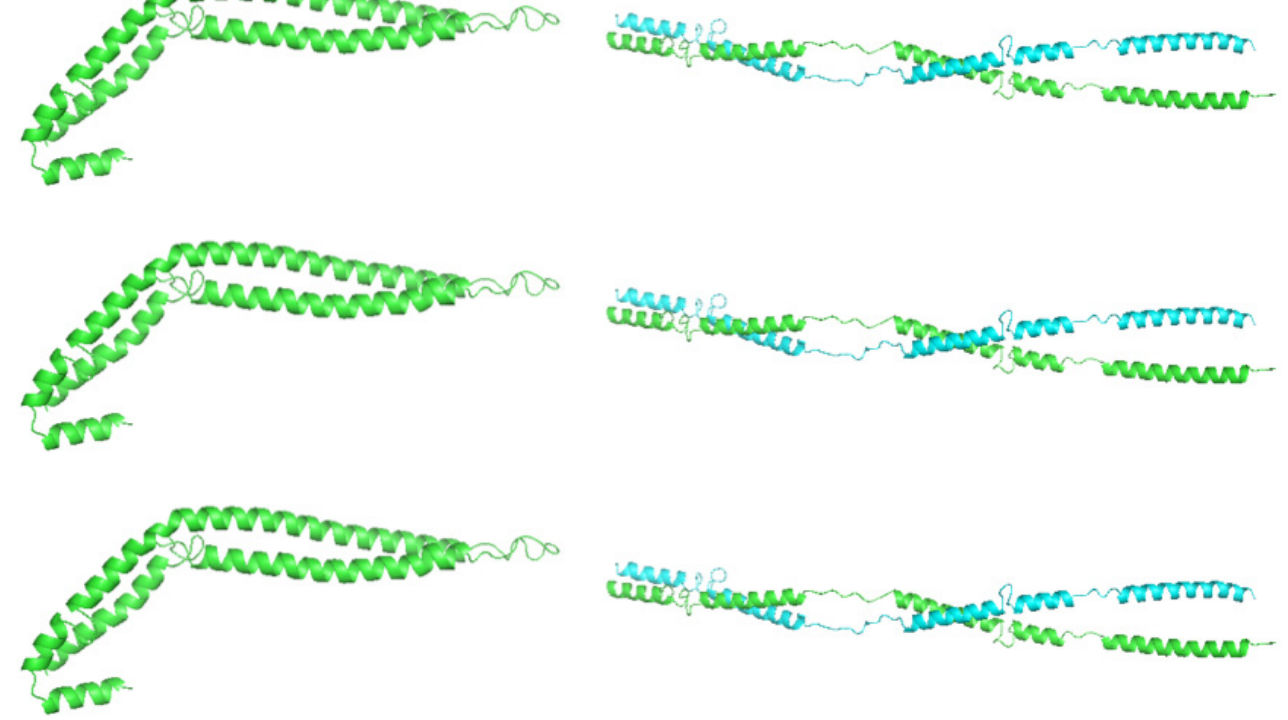

C)

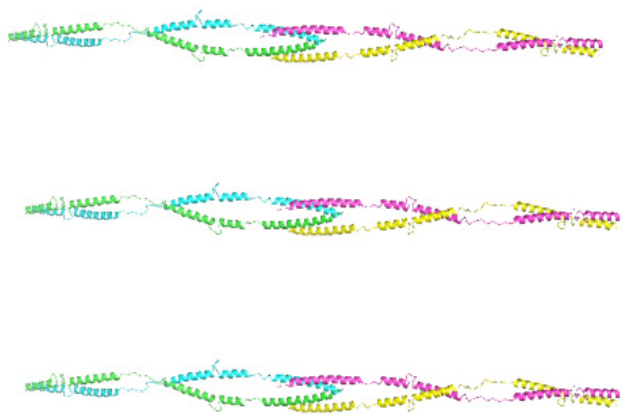

D)
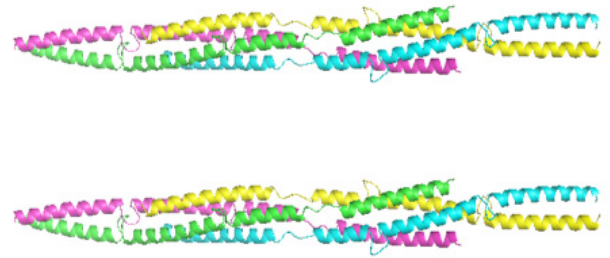

Figure 12.

SWISS-MODEL generated models have been used to generate an Amot80 ACCH domain homology model using HP0958 (A), dimeric ModelS24 (B), and tetrameric ModelS20 (C) and ModelS26. 
Table 8.

Models Generated Using LOMETS

\begin{tabular}{|c|c|c|c|c|c|c|c|c|}
\hline \multirow{2}{*}{ Model } & \multirow{2}{*}{$\begin{array}{l}\text { Protein } \\
\text { Template } \\
\text { (PDB ID) }\end{array}$} & \multirow{2}{*}{$\begin{array}{c}\text { Domain } \\
\text { Character }\end{array}$} & \multirow{2}{*}{ Function } & \multirow{2}{*}{ RMSD } & \multicolumn{3}{|c|}{ Z-score } & \multirow{2}{*}{$\begin{array}{l}\text { TM- } \\
\text { Score }\end{array}$} \\
\hline & & & & & Amot80 & AmotL1 & AmotL2 & \\
\hline ModelT01 & $\begin{array}{c}\text { NUDEL } \\
(2 \mathrm{~V} 71)\end{array}$ & Simple Helix & $\begin{array}{c}\text { Microtubule } \\
\text { Reorganization }\end{array}$ & 5.55 & 8.60 & 13.39 & 3.08 & 0.854 \\
\hline ModelT02 & $\begin{array}{c}\text { Tropomyosin } \\
\text { a-chain (2TMA) }\end{array}$ & Simple Helix & $\begin{array}{c}\text { Muscle } \\
\text { Contraction } \\
\end{array}$ & 4.41 & 21.30 & 74.22 & 89.40 & 0.851 \\
\hline ModelT08 & $\begin{array}{c}\text { Atg Complex } \\
\text { (4HPQ) }\end{array}$ & Coiled-coil & $\begin{array}{c}\text { Microtubule } \\
\text { Reorganization }\end{array}$ & 5.31 & 14.50 & 74.80 & 88.50 & 0.590 \\
\hline ModelT04 & $\begin{array}{c}\text { Tropomyosin } \\
\text { a-chain }(1 \mathrm{C} 1 \mathrm{G})\end{array}$ & Simple Helix & $\begin{array}{c}\text { Muscle } \\
\text { Contraction }\end{array}$ & 7.76 & 21.99 & 18.74 & 15.19 & 0.371 \\
\hline ModelT05 & $\begin{array}{c}\text { DHR64 } \\
(5 \mathrm{CWM})\end{array}$ & Coiled-coil & $\begin{array}{c}\text { Domain } \\
\text { Investigation }\end{array}$ & 13.00 & 8.71 & N.D.* & N.D.* & 0.295 \\
\hline ModelT09 & $\begin{array}{c}\text { PcsB } \\
(4 \mathrm{CGK})\end{array}$ & Coiled-coil & $\begin{array}{l}\text { Ordered cell wall } \\
\text { separation in } \\
\text { bacterial infection }\end{array}$ & 2.47 & 15.0 & N.D.* & N.D.* & 0.217 \\
\hline
\end{tabular}

Table 9.

Models Generated Using I-TASSER

\begin{tabular}{|c|c|c|c|c|c|c|c|c|}
\hline \multirow{2}{*}{ Model } & \multirow{2}{*}{$\begin{array}{l}\text { Protein } \\
\text { Template } \\
\text { (PDB ID) }\end{array}$} & \multirow{2}{*}{$\begin{array}{l}\text { Domain } \\
\text { Character }\end{array}$} & \multirow{2}{*}{ Function } & \multirow{2}{*}{ RMSD } & \multicolumn{3}{|c|}{ C-score } & \multirow{2}{*}{$\begin{array}{l}\text { TM- } \\
\text { Score }\end{array}$} \\
\hline & & & & & Amot80 & AmotL1 & AmotL2 & \\
\hline ModelT06 & $\begin{array}{l}\text { Myosin } \\
(2 \mathrm{DFS})\end{array}$ & Coiled-coil & $\begin{array}{c}\text { Muscle } \\
\text { Contraction }\end{array}$ & 4.90 & -2.57 & N.D.* & N.D.* & 0.630 \\
\hline ModelT03 & $\begin{array}{c}\text { Tropomyson } \\
\alpha \text {-chain (2TMA) }\end{array}$ & Simple Helix & $\begin{array}{c}\text { Muscle } \\
\text { Contraction }\end{array}$ & 6.73 & -2.41 & N.D.* & N.D.* & 0.510 \\
\hline ModelT10 & $\begin{array}{c}\text { Atg Complex } \\
\text { (4HPQ) }\end{array}$ & Coiled-coil & $\begin{array}{c}\text { Domain } \\
\text { Investigation }\end{array}$ & 14.50 & -2.28 & -3.68 & -3.69 & 0.396 \\
\hline ModelT11 & $\begin{array}{c}\text { Tropomyosin } \\
\text { a-chain }(1 \mathrm{C} 1 \mathrm{G})\end{array}$ & Simple Helix & $\begin{array}{c}\text { Muscle } \\
\text { Contraction }\end{array}$ & 10.16 & -3.04 & -3.69 & -3.69 & 0.304 \\
\hline ModelT07 & $\begin{array}{c}\text { Ezra } \\
(4 \mathrm{UXV})\end{array}$ & Coiled-coil & $\begin{array}{c}\text { Bacterial } \\
\text { cell division }\end{array}$ & 18.76 & -2.90 & -3.47 & -3.47 & 0.518 \\
\hline
\end{tabular}

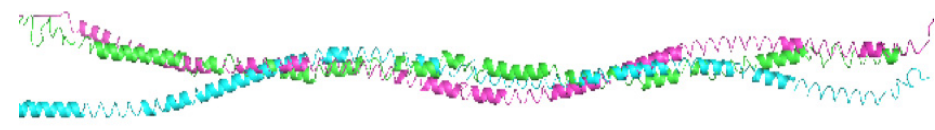

Figure 13.

Alignment of simple helix model leading candidates. Simple helix models ModelT01 (blue), ModelT02 (pink), and ModelT03 (green) were aligned for residues 90-190. (green) Model 03 - I-TASSER thread.

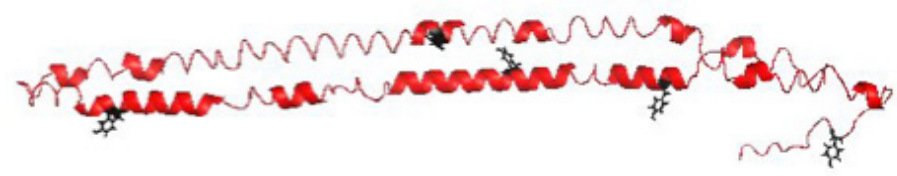

Figure 14.

Myosin threading model. Myosin V model generated by I-TASSER, with tyrosines shown in black to highlight potential lipid interaction. family are RhoA, NUDEL, Arfaptin, and HP0958. Crystallization studies show that RhoA, NUDEL, and HP0958 adopt a simple helix structure with a slight bend in the center of the domain, while Arfaptin coils on itself and upon dimerization forms a classic BAR domain crescent shape. NUDEL also appeared as a top model from the LOMETS threading software, further cementing that NUDEL was one of the best fits for the ACCH Domain.

\section{Model Selection}

The globular dimensions of the models generated were then compared against the experimental SAXS data using the ATSAS suite.

Generating dummy bead models. DAMMIN, DAMMIF and GASBOR were all used to construct ab initio low-resolution models from the SAXS. Each program was used to generate ten independent models that were then screened for spatial discrepancies and similarity using the DAMAVER suite. A representative model from DAMMIN, DAMMIF, and GASBOR are shown in Figure 16A-C, while Figure $16 \mathrm{D}$ shows the composite model generated by DAMAVER. This model suggests that the protein forms a dimer where the two legs of the protein repel each other so that the entire protein resembles a more "wishbone" shape. 


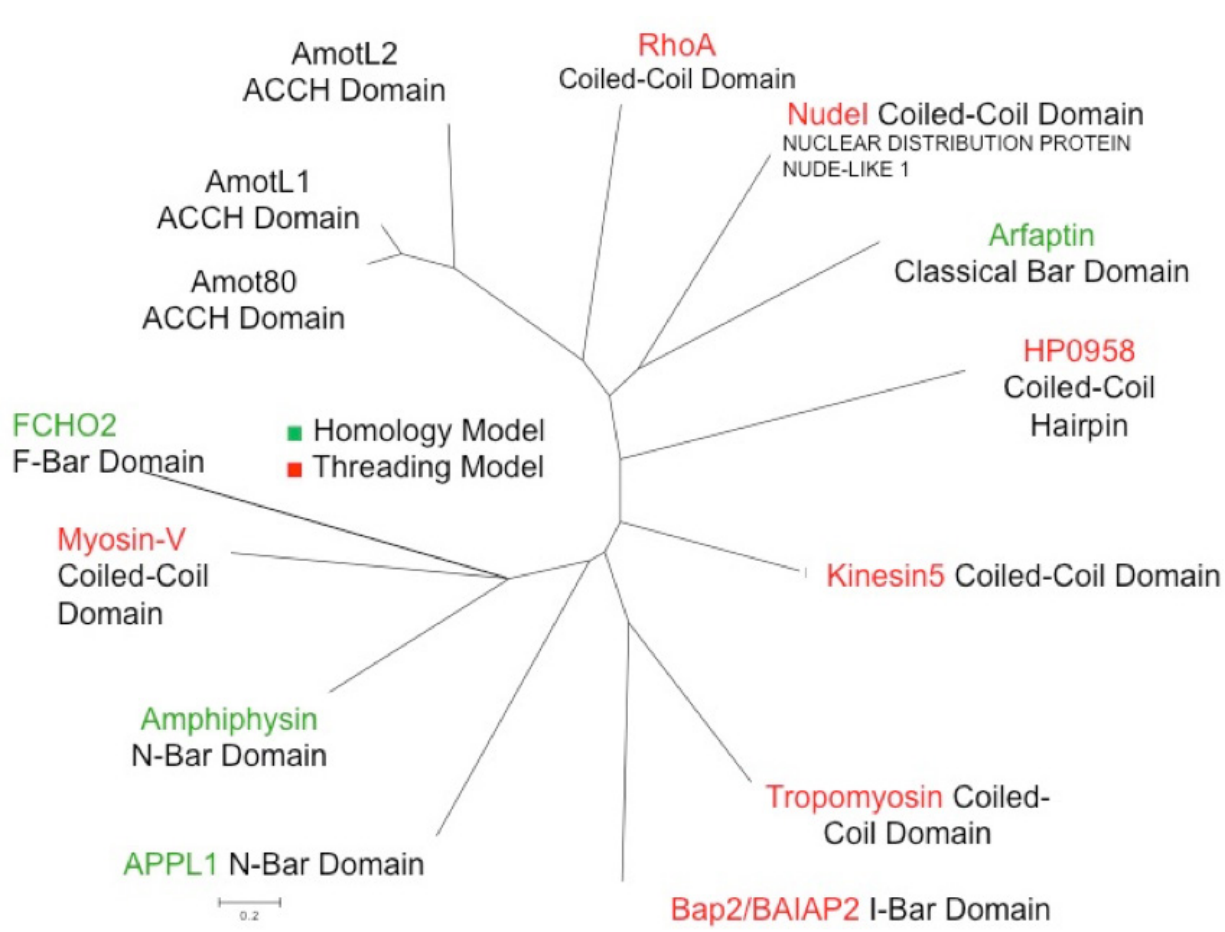

Figure 15.

Phylogeny tree. MEGA software phylogeny tree with AmotL1 and AmotL2 used for reference distance. The top threading and homology models were added to the table, in addition to one of each type of major BAR domain.

Comparing dummy bead to theoretical models. CRYSOL calculates a spherical radius for each model, which was then compared against the experimental data radius (Table 10/ Table 11). CRYSOL calculated a lower spherical radius than that generated with GNOM, however, it is very similar to the radius of the cylindrical rod. For consistency, the CRYSOL determined experimental radius of $13.96 \AA$ was used as a comparison for determining which theoretical structures should be considered. Furthermore, the template PDB files used to generate the models were also compared against the experimental data. Based on length, the experimental radius suggests that the $\mathrm{ACCH}$ domain is more similar in shape to the simple helix models than the coiled-coil models leading to closer analysis of ModelT01, ModelS20, and ModelH02 (spherical radii of 12.67, 13.27, and 13.12 ̊ respectively). SUPCOMB was used to align these models with that of the dummy bead model generated by DAMAVER. The shape of the DAMAVER model suggests that the threading model should be modified so that the legs of the model should be farther apart in solution. Therefore, the model was broken up into three chains (a head and two tails) thereby allowing for each chain to be individually moved and aligned with the DAMAVER dummy bead model using Coot. Using this approach, the terminal leg residues were moved from being $\sim 35 \AA\left(\sim 33^{\circ}\right)$ apart to $\sim 138 \AA\left(\sim 132^{\circ}\right)$ apart. As a result, CRYSOL calculates the radius of this model to be 12.74 $\AA$ for the dimer which is much larger than all the other dimeric homology models in Table 10. However, the homology tetramer models generated are slightly larger than ModelT01 because the legs provide much of the oligomeric overlap for the models.

\section{DISCUSSION}

\section{Template Selection}

Modulating Amot function has proven to be a key point in determining normal versus cancerous cellular phenotypes and growth patterns. We hypothesized that understanding the structural elements involved in the ACCH domain would be important in the regulation of Amot function. Therefore, we employed several techniques to determine the theoretical structure of the ACCH domain. We followed the Figure 1 threading protocol to select models that could be further refined by our experimental SAXS data. Initial attempts to create a homology model were unsuccessful as the sequence identities of templates generated by SWISS-PROT and BLAST searches were less than $<20 \%$. Therefore, we utilized the
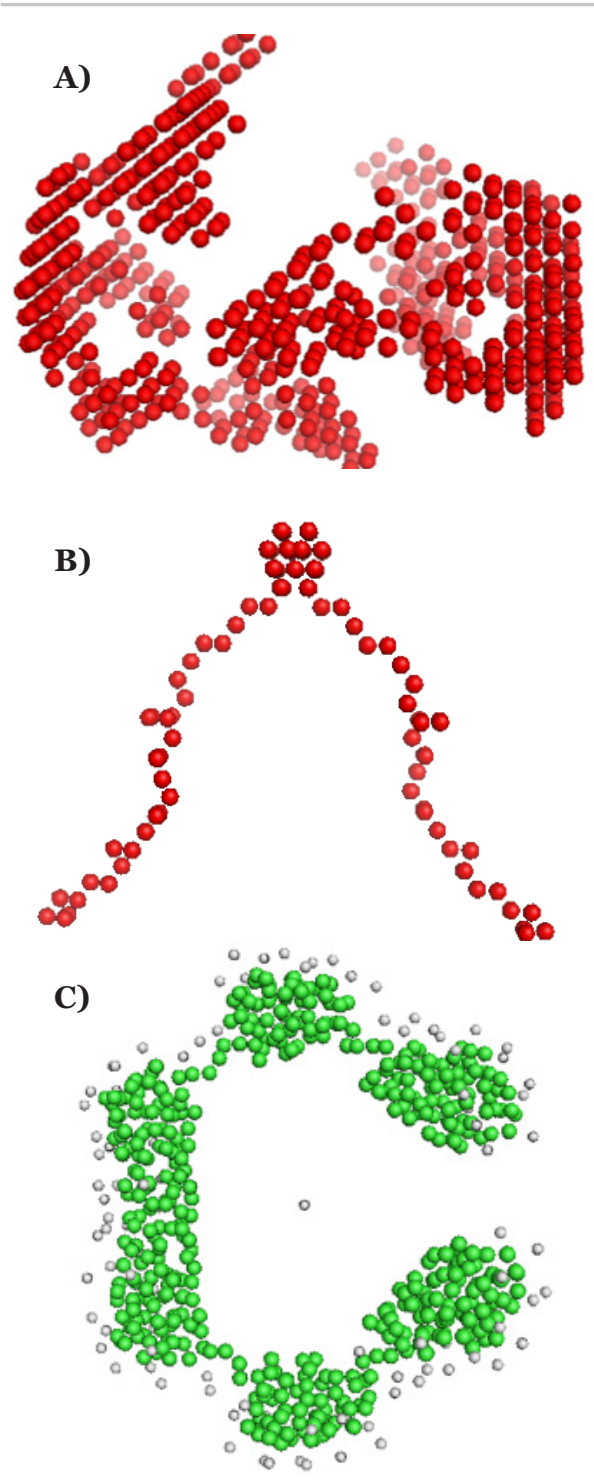

D)

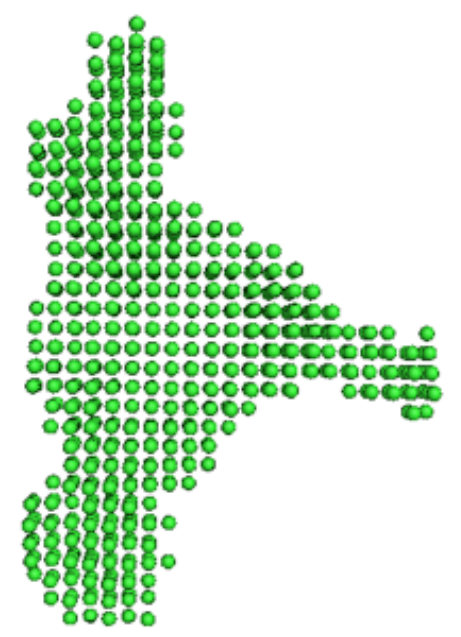

Figure 16.

ATSAS generated dummy bead models. Dummy bead models of the ACCH domain structure generated by DAMMIN (A), DAMMIF (B), GASBOR (C), and DAMAVER(E). 
Table 10.

Theoretical Globular Dimensions of Simple Alpha Helix Templates and Models as Determined by CRYSOL

\begin{tabular}{|c|c|c|c|c|c|c|}
\hline Model (PDB) & $\begin{array}{l}\text { Protein } \\
\text { Template } \\
\text { (PDB ID) }\end{array}$ & \# Residues & $\begin{array}{c}\text { Spherical } \\
\text { Radius ( }(\AA)\end{array}$ & $\begin{array}{c}\text { Rod } \\
\text { Radius }(\AA)\end{array}$ & $\begin{array}{c}\text { Rod } \\
\text { Length }(\AA)\end{array}$ & $\begin{array}{l}\text { Experimental Fit } \\
\qquad\left(\mathrm{X}^{2}\right)\end{array}$ \\
\hline \multirow{2}{*}{$\begin{array}{c}\text { Tropomyosin } \\
\text { a-chain }\end{array}$} & $1 \mathrm{C} 1 \mathrm{G}$ & 284 & 14.77 & 11.1 & 532.8 & 601.01 \\
\hline & 2TMA & 284 & 13.99 & 12.7 & 409.5 & 471.44 \\
\hline Experimental & N/A & 244 & 13.96 & $16.98 \pm .04$ & $651 \pm 2$ & - \\
\hline Myosin-V & 2DFS & 129 & 13.50 & 16.6 & 653.0 & 417.17 \\
\hline ModelS20 & $\mathrm{N} / \mathrm{A}$ & 136 & 13.27 & 17.2 & 213.2 & 520.23 \\
\hline ModelHo2 & $\mathrm{N} / \mathrm{A}$ & 158 & 13.12 & 17.2 & 213.2 & 530.50 \\
\hline Atg & 4HPQ & 79 & 13.04 & 20.1 & 332.8 & 602.41 \\
\hline ModelT01 & $\mathrm{N} / \mathrm{A}$ & 236 & 12.67 & 12.4 & 386.1 & 372.47 \\
\hline ModelHo1 & $\mathrm{N} / \mathrm{A}$ & 158 & 10.82 & 17.2 & 213.2 & 443.98 \\
\hline NUDEL & 2 V71 & 167 & 10.54 & 15.3 & 235.1 & 442.41 \\
\hline ModelS23 & $\mathrm{N} / \mathrm{A}$ & 136 & 10.26 & 17.2 & 213.2 & 401.25 \\
\hline ModelS24 & $\mathrm{N} / \mathrm{A}$ & 136 & 10.21 & 17.2 & 213.2 & 444.88 \\
\hline ModelS26 & $\mathrm{N} / \mathrm{A}$ & 136 & 9.46 & 17.2 & 213.2 & 516.14 \\
\hline EEA1_FYVE & 1JOC & 122 & 7.31 & 14.1 & 104.9 & 342.57 \\
\hline RhoA & $1 \mathrm{UIX}$ & 68 & 7.14 & 14.2 & 101.8 & 341.20 \\
\hline $\begin{array}{l}\text { SPTB2 (PH } \\
\text { Domain) }\end{array}$ & $1 \mathrm{BTN}$ & 106 & 4.93 & 36.6 & 33.9 & 469.62 \\
\hline
\end{tabular}

predicted folds of Amot80 to match with approximately 1300 different folds reported in the PDB using threading software. We then compared the yielded models based on software rank, sequence similarity, sequence identity, RMSD, and redundancy in template selection. As a result, ten models were described and ranked. Several of these templates had structural features in common that made it easy to collect them into groups. The models generated with the various software packages are derived from templates with either simple alpha helices or multiple alpha helical folds which we have termed coiled coil as their crystal structure. Initially, ModelT03 was selected as the best model due to the best C-score of -2.41, TM-score of $0.43 \pm 0.14$, and RMSD of $11.3 \pm 4.5 \AA$. The model is extremely similar to the crystal structure of the coiled-coil protein tropomyosin (2TMA \& $1 \mathrm{C} 1 \mathrm{G}$ ) and has $94 \%$ structural similarity. When compared against the SAXS data, though, this model was considerably too small to accurately fit the globular fit. The dimer fit of ModelT01, where NUDEL is the template, was much better to the SAXS globular envelope. The RMSD value for this model against NUDEL was also slightly better than the RMSD for 2TMA: 5.55 compared to 5.58, however, the structural coverage was $70 \%$ compared to $94 \%$ with tropomyosin. Tropomyosin had a sequence similarity of $14 \%$, and NUDEL had a similarity of $22 \%$. NUDEL was also a thread for all three Amot family members, while Tropomyosin (2TMA) only was associated with Amot80. On the phylogeny tree, NUDEL is also much closer to the Amot family members than Tropomyosin, a result of the sequence similarity. Compared to the Myosin-V model, as shown in Table 10, the NUDEL model is a much better fit for the SAXS data while the Myosin-V derived model radius is too short. The NUDEL model also better matches the secondary structure predicted with COILS2 in Figure 10, and multiple secondary structure prediction software in Figure 11. As a result, NUDEL was used as the thread PDB for the top simple helix model for the remainder of the project. However, it should be noted that the error between the experimental SAXS curves and the theoretical curves generated by CRYSOL is significant as determined by the $\chi^{2}$ values in Table 10 and Table 11 . Based on the dimensions presented, the radius is within the range of the experimental data. The experimental rod length suggests that the protein may be existing as an even higher ordered oligomer that tetramers at this concentration, potentially even as a dodecamer. This polymeric behavior has also been reported for NUDEL and based on the concentration dependence of the SAXS profiles (Figure 7) should be expected. Future work should include a comparison of higher oligomer states for this model against the SAXS data to look for a decrease in the theoretical curve error to confirm this model. 


\section{NATURAL SCIENCES}

Table 11.

Theoretical Globular Dimensions of Coiled-Coil Template and Models as Determined by CRYSOL

\begin{tabular}{|c|c|c|c|c|c|c|}
\hline Model (PDB) & $\begin{array}{l}\text { Protein } \\
\text { Template } \\
\text { (PDB ID) }\end{array}$ & \# Residues & $\begin{array}{c}\text { Spherical } \\
\text { Radius (§̊) }\end{array}$ & $\begin{array}{c}\text { Rod } \\
\text { Radius }(\AA)\end{array}$ & $\begin{array}{c}\text { Rod } \\
\text { Length }(\AA)\end{array}$ & $\begin{array}{l}\text { Experimental Fit } \\
\qquad\left(\mathrm{X}^{2}\right)\end{array}$ \\
\hline Experimental & $\mathrm{N} / \mathrm{A}$ & 244 & 13.96 & $\begin{array}{c}16.98 \pm \\
0.04\end{array}$ & $651 \pm 2$ & - \\
\hline Kinesin & 4PXT & 211 & 10.69 & 15.1 & 256.0 & 430.79 \\
\hline EzrA & $4 U X V$ & 535 & 10.06 & 15.2 & 141.5 & 518.95 \\
\hline ModelT08 & $\mathrm{N} / \mathrm{A}$ & 236 & 9.11 & 12.4 & 386.1 & 602.41 \\
\hline FCHO2 & 2V0O & 274 & 8.51 & 28.6 & 224.0 & 624.98 \\
\hline \multirow{2}{*}{ BAP2 } & $1 \mathrm{Y} 2 \mathrm{O}$ & 65 & 8.44 & 24.3 & 182.3 & 570.48 \\
\hline & 2YKT & 234 & 7.46 & 14.9 & 115.4 & 477.12 \\
\hline PesB & 4CGK & 392 & 8.26 & 95.2 & 162.2 & 619.01 \\
\hline Arfaptin & $1 \mathrm{I} 49$ & 200 & 8.12 & 17.3 & 161.5 & 536.62 \\
\hline APPL1 & 2Q12 & 259 & 7.88 & 16.1 & 148.3 & 443.96 \\
\hline ModelT06 & $\mathrm{N} / \mathrm{A}$ & 236 & 7.70 & 12.4 & 386.1 & 417.07 \\
\hline \multirow{2}{*}{ Amphiphysin } & $3 \mathrm{SOG}$ & 235 & 7.10 & 13.2 & 106.7 & 444.08 \\
\hline & 2RMY & 34 & 5.07 & 5.4 & 45.3 & 146.23 \\
\hline
\end{tabular}

A)

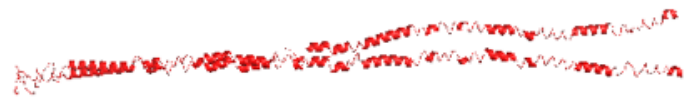

C) Helix 1

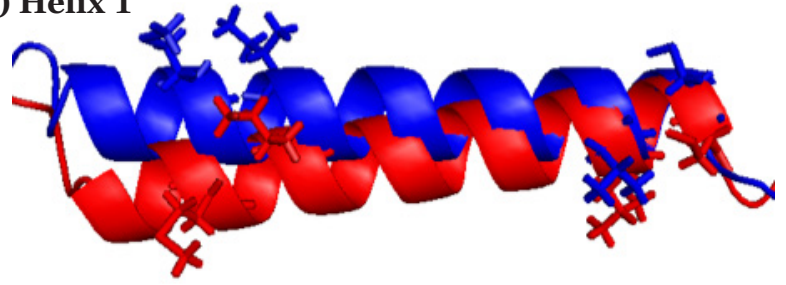

E) Helix 3

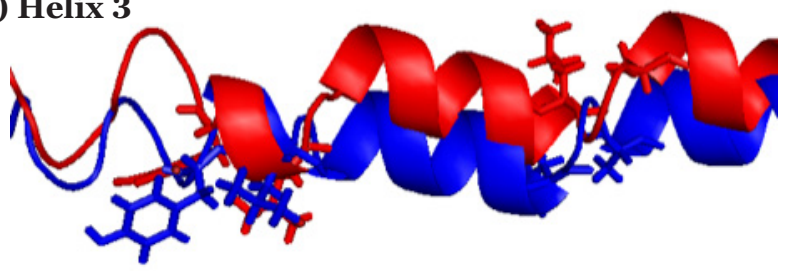

B)

D) Helix 2

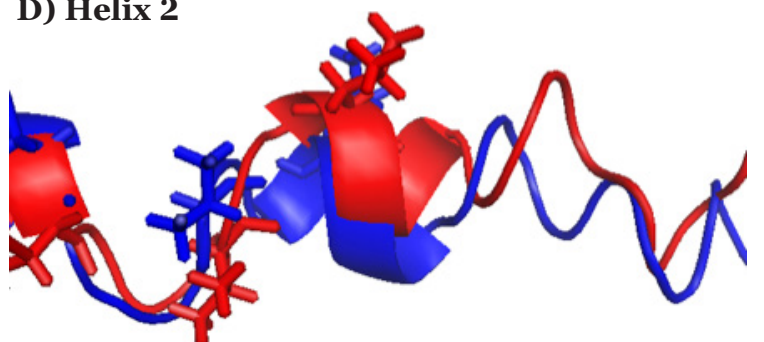

F) Helix 4

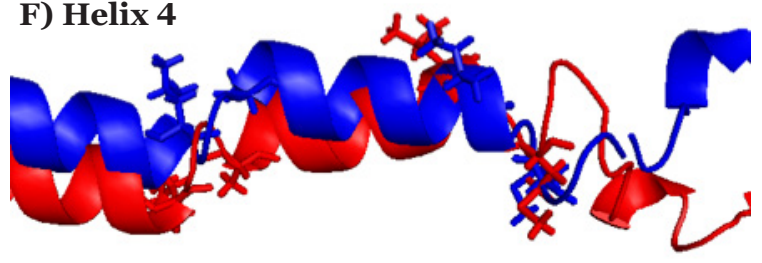

Figure 17.

ModelT01 structure as a dimer. (A) Shows NUDEL template-aligned dimer formation of ACCH Domain. (B) Shows model after the head and legs were aligned with the DAMAVER globular shape. Finally, the dimer interface is highlighted to show the regions of the heptads that stabilize the dimer: interface \#1 which includes residues 29-50 (MVEILSD)ENRNLRQE(LEGCYEK) (C), interface \#2 which includes residues 51-57 (VARLQKV) (D), interface \#3 which includes residues 68-87 (YENLVKS)SSKREA(LEKAMRN) (E), and interface \#4 which includes residues 93-99 (IRRMHDF) (F). 


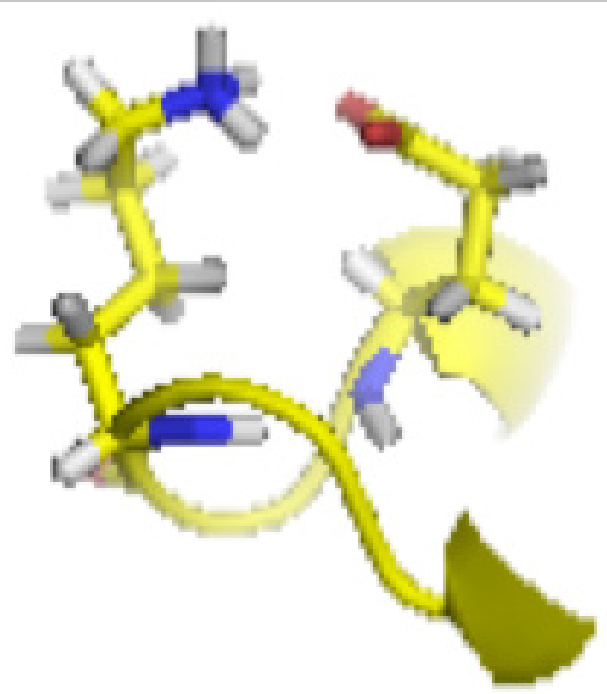

Figure 18.

Lys180 interacts with Glu182 to stabilize ACCH domain shape and therefore affinity for PI lipids. This figure shows how residues within the legs of the $A C C H$ domain can interact and therefore stabilize the alpha helices in this conformation for this dimer. The nitrogen of Lys180 is within $3 \AA$ of the Glu182 carboxyl oxygens suggesting that they directly interact forming an electrostatic bond.
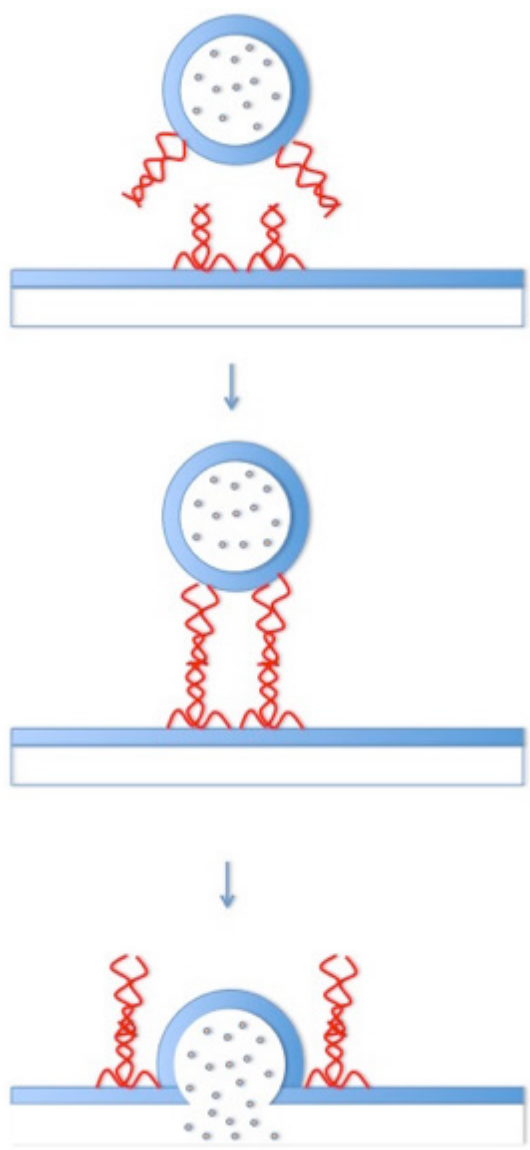

Figure 19.

Suggested mechanism for Amot related vesicle fusion. Proposed mechanism for the ACCH domain fuses juxtanuclear recycling endosomes with the apical membrane via a SNARE-like pathway.

Peck: Predicted Structure of the Amot Coiled Coil Homology
Dimer and Tetramer interface. The model chosen from threading is a dimer. In this model, the ACCH domain dimerizes at the N-terminus end, and has a closed linear conformation from residues 1-95. The confirmation is a simple alpha helix. From residues 95-107, the dimer continues to open up in a V-shape with open tails. The bend in the helix of that leads to the separation of the legs is rich in random coil residues. After the bend, it continues to be alpha helical in nature with small regions of random coil.

Hallmark coiled coil. NUDEL has approximately 12-seven amino acid repeat regions high in hydrophobic content that form a "knobsinto-holes" interconnected tertiary structure in its N-terminus (Derewenda et al., 2007). The ACCH domain structure generated here has a similar interconnected patch from residues 29-99. The individual alpha helical heptads, an amino acid sequence that follows the abcdefg pattern where residues $\mathbf{a}$ and $\mathbf{d}$ are hydrophobic (Burkhard, Stetefeld, \& Strelkov, 2001; Singh \& HitchcockDeGregori, 2003), that stabilize the dimer include (Figure 17C-F): residues 29-35 (MVEILSD), residues 44-50 (LEGCYEK), residues 51-57 (VARLQKV), residues 68-75 (YENLVKS), residues 80-87 (LEKAMRN), and 93-99 (IRRMHDF). Residues 100-106 then form a random coil region that then connects to the legs of the protein. Mutations made in this dimer interface that led to small reductions in lipid binding are all located in random coil regions in between the heptad stretches. Charge reversal mutations probably reduced the ability of the coiled coils to twist along itself, as this could create an electrostatic bond between residues within the random coil and corresponding heptad on the other side of the dimer interface.

\section{Template Insight into Functional Regions of Domain}

The SAXS data collected in conjunction with the dimensions of models generated suggests that like NUDEL the ACCH domain predominantly forms dimers in solution. The model suggested in this work confirms the previously reported alpha helical and coiled nature of the domain (Heller et al., 2010), where the globular structure could be described as a long cylinder and not quite the crescent shape of most BAR domains (Peter et al., 2004). In its native state, NUDEL has also been shown to form parallel homodimers forming a stable interface for known binding interactions at the C-terminus LIS1 binding site (Tarricone et al., 2004). In the ACCH domain structure, the C-terminal region begins with residue 105, which is beyond the flexible random coil region trailing from the interlocking interface. The C-terminus of NUDEL is in a "bent back" conformation in the dimeric forms (Soares et al., 2012) and has influenced the predicted structure of the ACCH domain to do so as well. Additionally, it has previously reported that this C-terminal region in NUDEL is able to form antiparallel helical bundles which serve as the tail-to-tail "tetramerization" interface when tightly packed in a crystal and or when interacting with DISC1(Narayanan, Arthanari, Wolfe, \& Wagner, 2011; Soares et al., 2012) or is unstable in solution (Derewenda et al., 2007). This flexible C-terminus region most likely drives the lipid binding and membrane fusion activity of Amot.

ACCH legs hypothesized to drive in lipid affinity. Characterization of the residues of the c-terminus of the ACCH domain gives further insight into how this region may drive interaction with lipids. The legs of the protein (residues 107-236) are $~ 24 \%$ basic resulting in a positive charge of 3.4 and $\sim 30 \%$ hydrophobic. When compared to the peptide tiling results, this suggests that the legs of this protein dominate lipid interactions and that the large spacing angle increases the probability of that interaction. This result is further substantiated 
by the effect of charge in Lys180. In the spot blot experiments, the reversal of charge in Lys180 led to a drastic decrease in lipid binding affinity. Lys180 lies within a KVVKLEEELKKK sequence that is highly charged region of the protein that has a charge-charge interaction with Glu182 (Figure 18). The mutation K180E mutation would obliterate this interaction and repel this interaction. This repulsion likely causes the remainder of the leg to bend back towards the other leg, thereby decreasing the ability of lipids to fit in between the dimer legs, resulting in a decreased lipid affinity.

Hypothesized mechanism for Amot related vesicle fusion. The $\mathrm{ACCH}$ domain is known to drive the functional ability of Amot to associate with phosphoinositol and cholesterol containing membranes. The ACCH Domain also drives the fusion of endocytotic vesicles to the apical membrane, however, the mechanism by which this fusion activity occurs has not been fully described. The template models generated based on sequence similarity may provide some insight into how this domain drives vesicle fusion. 5 of the 10 templates are known for participating in motor machinery for myosin-actin related muscle contraction. The high $(>90 \%)$ helical percentage of the tropomyosin chains are an optimal environment for a stable coiled-coil interaction via hydrophobic and electrostatic interactions (Cohen, 1963), (Jurasek, 1972). Specifically, the head to tail coiled-coil overlap region is important in allowing tropomyosin to rotate so that actin can bind during a muscle contraction (Smillie, 1981). Myosin's coiled-coil tail domain is equally as important, functioning to keep the myosin heads oriented and spaced correctly across the muscle filament. (Burkhard et al., 2001). Similarly, NUDEL's coiled-coil domain allows it to unwind and bind Lis1, allowing NUDEL to target dynein towards the plus end of microtubules. (Kimberley J. Sweeney, 2001) All of the mechanisms of these proteins are similar in that their coiled-coil domains contribute to the flexibility of protein to move related to its function. This comparison could provide insight into how Amot functionally drives vesicle fusion. Amot needs a mechanism that allows it to merge with the membrane, and the flexibility of a coiledcoil domain combined with its stability makes it extremely similar to the aforementioned proteins. Given the similarity to other coiledcoil domains, the mechanism should be comparable to the activity of a SNARE protein/complex, which consists of a heterotetramerich coiled-coil (Burkhard et al., 2001). We present a theoretical model based on our data (Figure 19) where Amot is located on the incoming vesicle and the target vesicle membrane. When the vesicles are close enough, the ACCH domain dimer form can interact to form a tetramer, bringing the membranes together in a twisting motion. To reiterate, this model is merely speculation given the similarities between Amot's $\mathrm{ACCH}$ domain and coiled-coil flexible protein domains.

\section{CONCLUSION}

The work presented here is focused on determining the structure of the ACCH domain of the angiomotins, and correlating that structure with its lipid binding function. In general, the ACCH domain has a low sequence identity with the crystal structures that have been deposited in the Protein Database. However, several models were generated based on similarity in charge and hydrophobic amino acid distribution. The structural model presented was developed by selectively screening those models using globular dimensions determined from experimental SAXS data, followed by further refinement using a dummy bead model generated in parallel based on the SAXS scattering profile. This resulted in a dimer model where the dimer interface occurs in the N-terminus in a similar manner as the coiled coil regions of NUDEL and the myosin family of proteins. Furthermore, the c-terminus forms the legs of the dimer which spread apart from one another. The combination of the model and spot blot assay data presented suggests that these legs are the involved ends of the domain, performing the lipid binding function. Finally, the similarity of this coiled coil model with those reported in the templates used to generate this model suggests that the coiled coil is able to entwine and bring multiple membrane surfaces close to one another which would then lead to membrane deformation and later vesicle fusion. This study suggests the mechanistic hypothesis as to how Amot80 drives the fusion of juxtanuclear recycling endosomes to the apical membrane of epithelial cells and should guide future studies of Amot family members during cellular polarity studies.

\section{ACKNOWLEDGEMENTS}

The manuscript was written through contributions of all authors. A.K.-H. initiated and designed the study, performed experiments, data analysis and manuscript preparation; C.P. and P.V. performed theoretical modeling of structure. D.E.J. created and analyzed data for peptide spot blots used in this study. Special thanks to Drs. Thomas Hurley (Indiana University School of Medicine) for discussions regarding template selection and energy minimization of residues within select models. Special thanks to Drs. Millicent Firestone (Los Alamos National Laboratory) and Horia Petrache (Indiana University Purdue University Indianapolis) for discussions on the analysis of SAXS data. GST constructs used in this study were a gift from Clark Wells (Indiana University School of Medicine). Instrumentation used in this study were a part of the Indiana University School of Medicine Department of Biochemistry and Molecular Biology core facilities. This work was supported, in part, by National Institutes of Health Grants K01-CA169078-01 (to A.K.H.) and Indiana University Purdue University Indianapolis Undergraduate Research Opportunity Program Research Grants (to C.P. and P.V.). The authors declare no competing financial interest. Results shown in this report are derived from work performed at X-ray Science Division at the Advanced Photon Source Argonne National Laboratory. The authors would like to thank Soenke Seifert for his assistance at XRD 12ID. Argonne was operated by UChicago Argonne, LLC, for the U.S. Department of Energy, Office of Biological and Environmental Research under contract DE-AC02-06CH11357.

\section{AUTHOR INFORMATION}

All correspondence should be sent to the senior author: ankimble@iu.edu

\section{REFERENCES}

Aase, K., Ernkvist, M., Ebarasi, L., Jakobsson, L., Majumdar, A., Yi, C., . . Holmgren, L. (2007). Angiomotin regulates endothelial cell migration during embryonic angiogenesis. Genes \& Development, 21(16), 2055-2068. doi:10.1101/gad.432007

Albrecht, L. V., Green, K. J., \& Dubash, A. D. (2016). Cadherins in Cancer. In S. T. Suzuki \& S. Hirano (Eds.), The Cadherin Superfamily: Key Regulators of Animal Development and Physiology (pp. 363-397). Tokyo: Springer Japan.

Ali, M. F., Chachadi, V. B., Petrosyan, A., \& Cheng, P.-W. (2012). Golgi Phosphoprotein 3 Determines Cell Binding Properties under Dynamic Flow by Controlling Golgi Localization of Core $2 \mathrm{~N}$-Acetylglucosaminyltransferase 1. Journal of Biological Chemistry, 287(47), 39564-39577. doi:10.1074/jbc. M112.346528 
Arnau, J., Lauritzen, C., Petersen, G. E., \& Pedersen, J. (2006). Current strategies for the use of affinity tags and tag removal for the purification of recombinant proteins. Protein Expression and Purification, 48(1), 1-13. doi:http://dx.doi. org/10.1016/j.pep.2005.12.002

Arnold, K., Bordoli, L., Kopp, J., \& Schwede, T. (2006). The SWISS-MODEL workspace: a web-based environment for protein structure homology modelling. Bioinformatics, 22(2), 195-201. doi:10.1093/bioinformatics/bti770

Ashpole, N. M., \& Hudmon, A. (2011). Excitotoxic neuroprotection and vulnerability with CaMKII inhibition. Molecular and Cellular Neuroscience, 46(4), 720-730. doi:http://dx.doi.org/10.1016/j.mcn.2011.02.003

Biasini, M., Bienert, S., Waterhouse, A., Arnold, K., Studer, G., Schmidt, T., .. . Schwede, T. (2014). SWISS-MODEL: modelling protein tertiary and quaternary structure using evolutionary information. Nucleic acids research, 42(W1), W252-W258. doi:10.1093/nar/gku340

Bobba, S., Ponnaluri, V. K. C., Mukherji, M., \& Gutheil, W. G. (2011). Microtiter Plate-Based Assay for Inhibitors of Penicillin-Binding Protein 2a from Methicillin-Resistant Staphylococcus aureus. Antimicrobial Agents and Chemotherapy, 55(6), 2783-2787. doi:10.1128/aac.01327-10

Buchan DWA, M. F., Nugent TCO, Bryson K, Jones DT. (2013). Scalable web services for the PSIPRED Protein Analysis Workbench. Nucleic Acids Research, 41(W1), W340-W348.

Burkhard, P., Stetefeld, J., \& Strelkov, S. V. (2001). Coiled coils: a highly versatile protein folding motif. Trends in Cell Biology, 11(2), 82-88. doi:http://dx.doi.org/10.1016/S09628924(00)01898-5

Cha, R., \& Tilly, W. (1995). PCR primer: Cold Spring Harbor Laboratory, Cold Spring Harbor, NY.

Chan, S. W., Lim, C. J., Chong, Y. F., Pobbati, A. V., Huang, C., \& Hong, W. (2011). Hippo Pathway-independent Restriction of TAZ and YAP by Angiomotin. The Journal of Biological Chemistry, 286(9), 7018-7026. doi:10.1074/jbc.C110.212621

Cohen, C. a. H., K. (1963). J. Mol. Bio, 6, J. Mol. Bio.

Colwill, K., Wells, C. D., Elder, K., Goudreault, M., Hersi, K., Kulkarni, S., . . . Morin, G. B. (2006). Modification of the Creator recombination system for proteomics applicationsimproved expression by addition of splice sites. $B M C$ biotechnology, 6(1), 13. doi:10.1186/1472-6750-6-13

Cowtan, P. E. a. B. L. a. W. G. S. a. K. (2010). Features and Development of Coot. Acta Crystallographica Section D Biological Crystallography, 66, 486-501.

Dawson, J. C., Legg, J. A., \& Machesky, L. M. (2006). Bar domain proteins: a role in tubulation, scission and actin assembly in clathrin-mediated endocytosis. Trends in Cell Biology, 16(10), 493-498.

Derewenda, U., Tarricone, C., Choi, W. C., Cooper, D. R., Lukasik, S., Perrina, F., . . . Derewenda, Z. S. (2007). The Structure of the Coiled-Coil Domain of Ndel1 and the Basis of Its Interaction with Lis1, the Causal Protein of Miller-Dieker Lissencephaly. Structure, 15(11), 1467-1481. doi:http:// dx.doi.org/10.1016/j.str.2007.09.015
Ellmark, P., Ingvarsson, J., Carlsson, A., Lundin, B. S., Wingren, C., \& Borrebaeck, C. A. K. (2006). Identification of Protein Expression Signatures Associated with Helicobacter pylori Infection and Gastric Adenocarcinoma Using Recombinant Antibody Microarrays. Molecular \& Cellular Proteomics, 5(9), 1638-1646. doi:10.1074/mcp.M600170MCP200

Ernkvist, M., Aase, K., Ukomadu, C., Wohlschlegel, J., Blackman, R., Veitonmäki, N., . . Holmgren, L. (2006). p130-Angiomotin associates to actin and controls endothelial cell shape. FEBS Journal, 273(9), 2000-2011. doi:10.1111/j.17424658.2006.05216.x

Ernkvist, M., Birot, O., Sinha, I., Veitonmaki, N., Nyström, S., Aase, K., \& Holmgren, L. (2008). Differential roles of p80and p130-angiomotin in the switch between migration and stabilization of endothelial cells. Biochimica et Biophysica Acta (BBA) - Molecular Cell Research, 1783(3), 429-437. doi:10.1016/j.bbamcr.2007.11.018

Flaman, J.-M., Frebourg, T., Moreau, V., Charbonnier, F., Martin, C., Ishioka, C., . . . Iggo, R. (1994). A rapid PCR fidelity assay. Nucleic acids research, 22(15), 3259.

Flory, P. J., \& Volkenstein, M. (1969). Statistical mechanics of chain molecules. Biopolymers, 8(5), 699-700. doi:10.1002/ bip.1969.360080514

Franke, D., \& Svergun, D. I. (2009). DAMMIF, a program for rapid ab-initio shape determination in small-angle scattering. Journal of Applied Crystallography, 42(2), 342-346. doi:doi:10.1107/S0021889809000338

Franke, T. F., Kaplan, D. R., Cantley, L. C., \& Toker, A. (1997). Direct Regulation of the Akt Proto-Oncogene Product by Phosphatidylinositol-3,4-bisphosphate. Science, 275(5300), 665-668. doi:10.1126/science.275.5300.665

Gallop, J. L., Jao, C. C., Kent, H. M., Butler, P. J. G., Evans, P. R., Langen, R., \& McMahon, H. T. (2006). Mechanism of endophilin N-BAR domain-mediated membrane curvature. The EMBO Journal, 25(12), 2898-2910. doi:10.1038/ sj.emboj.7601174

Goujon, M., McWilliam, H., Li, W., Valentin, F., Squizzato, S., Paern, J., \& Lopez, R. (2010). A new bioinformatics analysis tools framework at EMBL-EBI. Nucleic acids research, 38(suppl 2), W695-W699. doi:10.1093/nar/gkq313

Guex, N., Peitsch, M. C., \& Schwede, T. (2009). Automated comparative protein structure modeling with SWISSMODEL and Swiss-PdbViewer: A historical perspective. Electrophoresis, 30(S1), S162-S173. doi:10.1002/ elps.200900140

Hakami, F., Darda, L., Stafford, P., Woll, P., Lambert, D. W., \& Hunter, K. D. (2014). The roles of HOXD10 in the development and progression of head and neck squamous cell carcinoma (HNSCC). Br J Cancer, 111(4), 807-816. doi:10.1038/ bjc.2014.372

Heller, B., Adu-Gyamfi, E., Smith-Kinnaman, W., Babbey, C., Vora, M., Xue, Y., .. . Wells, C. D. (2010). Amot Recognizes a Juxtanuclear Endocytic Recycling Compartment via a Novel Lipid Binding Domain. Journal of Biological Chemistry, 285(16), 12308-12320. doi:10.1074/jbc.M109.096230 
Hinderliter, A., \& May, S. (2006). Cooperative adsorption of proteins onto lipid membranes. Journal of Physics: Condensed Matter, 18(28), S1257.

Hirate, Y., Hirahara, S., Inoue, K.-i., Suzuki, A., Alarcon, Vernadeth B., Akimoto, K., . . . Sasaki, H. (2013). PolarityDependent Distribution of Angiomotin Localizes Hippo Signaling in Preimplantation Embryos. Current Biology, 23(13), 1181-1194. doi:http://dx.doi.org/10.1016/j. cub.2013.05.014

Hirate, Y., \& Sasaki, H. (2014). The role of angiomotin phosphorylation in the Hippo pathway during preimplantation mouse development. Tissue Barriers, 2(1), e28127. doi:10.4161/tisb.28127

Hsu, Y. L., Hung, J. Y., Chou, S. H., Huang, M. S., Tsai, M. J., Lin, Y. S., . . . Kuo, P. L. (2015). Angiomotin decreases lung cancer progression by sequestering oncogenic YAP/TAZ and decreasing Cyr61 expression. Oncogene, 34(31), 4056-4068. doi:10.1038/onc.2014.333

Jaroszewski, L., Rychlewski, L., Li, Z., Li, W., \& Godzik, A. (2005). FFAS03: a server for profile-profile sequence alignments. Nucleic acids research, 33(suppl 2), W284-W288. doi:10.1093/nar/gki418

Jiang, W., Watkins, G., Douglas-Jones, A., Holmgren, L., \& Mansel, R. (2006). Angiomotin and angiomotin like proteins, their expression and correlation with angiogenesis and clinical outcome in human breast cancer. BMC Cancer, 6(1), 16.

Johnson, M. A., Seifert, S., Petrache, H. I., \& Kimble-Hill, A. C. (2014). Phase Coexistence in Single-Lipid Membranes Induced by Buffering Agents. Langmuir, 30(33), 9880-9885. doi:10.1021/la5018938

Jurasek, R. S. H. a. J. S. a. L. B. S. a. L. (1972). Bioinformatics, 37, 299.

Kiefer, F., Arnold, K., Künzli, M., Bordoli, L., \& Schwede, T. (2009). The SWISS-MODEL Repository and associated resources. Nucleic acids research, 37(suppl_1), D387-D392. doi:10.1093/nar/gkn750

Kimberley J. Sweeney, A. P., Gregor Eichele. (2001). NudE-L, a novel Lis1-interacting protein, belongs to a family of vertebrate coiled-coil proteins. Mechanisms of Development, 101(1-2).

Kozin, M. B., \& Svergun, D. I. (2001). Automated matching of high- and low-resolution structural models. Journal of Applied Crystallography, 34(1), 33-41. doi:doi:10.1107/ S0021889800014126

Leevers, S. J., Vanhaesebroeck, B., \& Waterfield, M. D. (1999). Signalling through phosphoinositide 3-kinases: the lipids take centre stage. Current Opinion in Cell Biology, 11(2), 219-225. doi:http://dx.doi.org/10.1016/S0955-0674(99)80029-5

Levchenko, T., Veitonmäki, N., Lundkvist, A., Gerhardt, H., Ming, Y., Berggren, K., . . . Holmgren, L. (2008). Therapeutic antibodies targeting angiomotin inhibit angiogenesis in vivo. The FASEB Journal, 22(3), 880-889. doi:10.1096/fj.07-9509com

LifeTein. Retrieved from http://lifetein.com/peptide-analysistool.html
Lobley, A., Sadowski, M. I., \& Jones, D. T. (2009). pGenTHREADER and pDomTHREADER: new methods for improved protein fold recognition and superfamily discrimination. Bioinformatics, 25(14), 1761-1767. doi:10.1093/bioinformatics/btp302

Lundberg, K. S., Shoemaker, D. D., Adams, M. W. W., Short, J. M., Sorge, J. A., \& Mathur, E. J. (1991). High-fidelity amplification using a thermostable DNA polymerase isolated from Pyrococcus furiosus. Gene, 108(1), 1-6. doi:http:// dx.doi.org/10.1016/0378-1119(91)90480-Y

Lupas, A., Van Dyke, M., and Stock, J. (1991). Predicting Coiled Coils from Protein Sequences. Science, 252, 1162-1164.

Lv, M., Li, S., Luo, C., Zhang, X., Shen, Y., Sui, Y., . . Yang, J. (2016). Angiomotin promotes renal epithelial and carcinoma cell proliferation by retaining the nuclear YAP. Oncotarget, 7(11), 12393-12403. doi:10.18632/oncotarget.7161

Madera, M. (2008). Profile Comparer: a program for scoring and aligning profile hidden Markov models. Bioinformatics, 24(22), 2630-2631. doi:10.1093/bioinformatics/btn504

Mana-Capelli, S., Paramasivam, M., Dutta, S., \& McCollum, D. (2014). Angiomotins link F-actin architecture to Hippo pathway signaling. Molecular Biology of the Cell, 25(10), 1676-1685. doi:10.1091/mbc.E13-11-0701

McLaughlin, S., Wang, J., Gambhir, A., \& Murray, D. (2002). PIP2 and proteins: Interactions, organization, and information flow. Annual review of biophysics and biomolecular structure, 31(1), 151-175.

Narayanan, S., Arthanari, H., Wolfe, M. S., \& Wagner, G. (2011). Molecular Characterization of Disrupted in Schizophrenia-1 Risk Variant S704C Reveals the Formation of Altered Oligomeric Assembly. Journal of Biological Chemistry, 286(51), 44266-44276. doi:10.1074/jbc. M111.271593

Ortiz, A., Lee, Y.-C., Yu, G., Liu, H.-C., Lin, S.-C., Bilen, M. A., . . . Lin, S.-H. (2015). Angiomotin is a novel component of cadherin- $11 / \beta$-catenin/p120 complex and is critical for cadherin-11-mediated cell migration. The FASEB Journal, 29(3), 1080-1091. doi:10.1096/fj.14-261594

Peter, B. J., Kent, H. M., Mills, I. G., Vallis, Y., Butler, P. J. G., Evans, P. R., \& McMahon, H. T. (2004). BAR Domains as Sensors of Membrane Curvature: The Amphiphysin BAR Structure. Science, 303(5657), 495-499. doi:10.1126/ science.1092586

Petrosyan, A., Ali, M. F., Verma, S. K., Cheng, H., \& Cheng, P.-W. (2012). Non-muscle myosin IIA transports a Golgi glycosyltransferase to the endoplasmic reticulum by binding to its cytoplasmic tail. The International Journal of Biochemistry \& Cell Biology, 44(7), 1153-1165. doi:http:// dx.doi.org/10.1016/j.biocel.2012.04.004

Ranahan, W. P., Han, Z., Smith-Kinnaman, W., Nabinger, S. C., Heller, B., Herbert, B.-S., . . . Wells, C. D. (2011). The Adaptor Protein AMOT Promotes the Proliferation of Mammary Epithelial Cells via the Prolonged Activation of the Extracellular Signal-Regulated Kinases. Cancer Research, 71(6), 2203-2211. doi:10.1158/0008-5472.can-10-1995 
Rong, S.-B., Hu, Y., Enyedy, I., Powis, G., Meuillet, E. J., Wu, X., . . Kozikowski, A. P. (2001). Molecular Modeling Studies of the Akt PH Domain and Its Interaction with Phosphoinositides. Journal of Medicinal Chemistry, 44(6), 898-908. doi:10.1021/jm000493i

Roy, A., Kucukural, A., \& Zhang, Y. (2010). I-TASSER: a unified platform for automated protein structure and function prediction. Nat. Protocols, 5(4), 725-738.

Ruan, W.-D., Wang, P., Feng, S., Xue, Y., \& Zhang, B. (2016). MicroRNA-497 inhibits cell proliferation, migration, and invasion by targeting AMOT in human osteosarcoma cells. OncoTargets and therapy, 9, 303-313. doi:10.2147/OTT. S95204

Ruan, W., Wang, P., Feng, S., Xue, Y., \& Li, Y. (2016). Long noncoding RNA small nucleolar RNA host gene 12 (SNHG12) promotes cell proliferation and migration by upregulating angiomotin gene expression in human osteosarcoma cells. Tumor Biology, 37(3), 4065-4073. doi:10.1007/s13277015-4256-7

Senes, A., Chadi, D. C., Law, P. B., Walters, R. F. S., Nanda, V., \& DeGrado, W. F. (2007). Ez, a Depth-dependent Potential for Assessing the Energies of Insertion of Amino Acid Side-chains into Membranes: Derivation and Applications to Determining the Orientation of Transmembrane and Interfacial Helices. Journal of Molecular Biology, 366(2), 436-448. doi:http://dx.doi.org/10.1016/j.jmb.2006.09.020

Shimono, A., \& Behringer, R. R. (2003). Angiomotin Regulates Visceral Endoderm Movements during Mouse Embryogenesis Current Biology, 13(7), 613-617

Shugar, D. (1952). The measurement of lysozyme activity and the ultra-violet inactivation of lysozyme. Biochim Biophys Acta, 8(0), 302-309. doi:http://dx.doi.org/10.1016/00063002(52)90045-0

Sievers F, W. A., Dineen DG, Gibson TJ, Karplus K, Li W, Lopez R, McWilliam H, Remmert M, Söding J, Thompson JD, Higgins DG. (2011). Fast, scalable generation of high-quality protein multiple sequence alignments using Clustal Omega. Molecular Systems Biology, 7(539).

Sievers, F., Wilm, A., Dineen, D., Gibson, T. J., Karplus, K., Li, W., . . . Higgins, D. G. (2011). Fast, scalable generation of high-quality protein multiple sequence alignments using Clustal Omega. Molecular Systems Biology, 7(1). doi:10.1038/msb.2011.75

Singh, A., \& Hitchcock-DeGregori, S. E. (2003). Local Destabilization of the Tropomyosin Coiled Coil Gives the Molecular Flexibility Required for Actin Binding. Biochemistry, 42(48), 14114-14121. doi:10.1021/ bi0348462

Sitao Wu, Y. Z. (2007). LOMETS: A local meta-threading-server for protein structure prediction. Nucleic Acids Research, 35, 3375-3382.

Smillie, A. S. M. a. L. B. (1981). Biochemistry, 4, 2401.

Soares, D. C., Bradshaw, N. J., Zou, J., Kennaway, C. K., Hamilton, R. S., Chen, Z. A., . . Porteous, D. J. (2012). The Mitosis and Neurodevelopment Proteins NDE1 and NDEL1
Form Dimers, Tetramers, and Polymers with a Folded Back Structure in Solution. Journal of Biological Chemistry, 287(39), 32381-32393. doi:10.1074/jbc.M112.393439

Söding, J. (2005). Protein homology detection by HMM-HMM comparison. Bioinformatics, 21(7), 951-960. doi:10.1093/ bioinformatics/bti125

Stenmark, H., Aasland, R., Toh, B.-H., \& D'Arrigo, A. (1996). Endosomal Localization of the Autoantigen EEA1 Is Mediated by a Zinc-binding FYVE Finger. Journal of Biological Chemistry, 271(39), 24048-24054. doi:10.1074/ jbc.271.39.24048

Stenmark, H., \& Gillooly, D. J. (2001). Intracellular trafficking and turnover of phosphatidylinositol 3-phosphate. Seminars in Cell and Developmental Biology, 12(2), 193-199.

Sugihara-Mizuno, Y., Adachi, M., Kobayashi, Y., Hamazaki, Y., Nishimura, M., Imai, T., . . Tsukita, S. (2007). Molecular characterization of angiomotin/JEAP family proteins: interaction with MUPP1/Patj and their endogenous properties. Genes to Cells, 12(4), 473-486. doi:10.1111/j.13652443.2007.01066.x

Svergun, D. (1992). Determination of the regularization parameter in indirect-transform methods using perceptual criteria. Journal of Applied Crystallography, 25(4), 495-503. doi:doi:10.1107/S0021889892001663

Svergun, D., Barberato, C., \& Koch, M. H. J. (1995). CRYSOL- a Program to Evaluate X-ray Solution Scattering of Biological Macromolecules from Atomic Coordinates. Journal of Applied Crystallography, 28(6), 768-773. doi:10.1107/ s0021889895007047

Svergun, D. I. (1999). Restoring Low Resolution Structure of Biological Macromolecules from Solution Scattering Using Simulated Annealing. Biophysical Journal, 76(6), 2879-2886. doi:http://dx.doi.org/10.1016/S0006-3495(99)77443-6

Svergun, D. I., Petoukhov, M. V., \& Koch, M. H. J. (2001). Determination of Domain Structure of Proteins from X-Ray Solution Scattering. Biophysical Journal, 80(6), 2946-2953.

Tamura K, D. J., Nei M \& Kumar S (2007). MEGA4: Molecular Evolutionary Genetics Analysis (MEGA) software version 4.0. Molecular Biology and Evolution, 24, 1596-1599.

Tamura, K., Stecher, G., Peterson, D., Filipski, A., \& Kumar, S. (2013). MEGA6: Molecular Evolutionary Genetics Analysis Version 6.0. Molecular Biology and Evolution, 30(12), 27252729. doi:10.1093/molbev/mst197

Tarricone, C., Perrina, F., Monzani, S., Massimiliano, L., Kim, M.H., Derewenda, Z. S., . . . Musacchio, A. (2004). Coupling PAF Signaling to Dynein Regulation: Structure of LIS1 in Complex with PAF-Acetylhydrolase. Neuron, 44(5), 809-821. doi:http:// dx.doi.org/10.1016/j.neuron.2004.11.019

Terpe, K. (2003). Overview of tag protein fusions: from molecular and biochemical fundamentals to commercial systems. Applied Microbiology and Biotechnology, 60(5), 523-533. doi:10.1007/s00253-002-1158-6

Vanhaesebroeck, B., \& Waterfield, M. D. (1999). Signaling by Distinct Classes of Phosphoinositide 3-Kinases. Experimental 
Cell Research, 253(1), 239-254. doi:http://dx.doi. org/10.1006/excr.1999.4701

Volkov, V. V., \& Svergun, D. I. (2003). Uniqueness of ab initio shape determination in small-angle scattering. Journal of Applied Crystallography, 36(3 Part 1), 860-864. doi:doi:10.1107/S0021889803000268

Wang, W., Huang, J., \& Chen, J. (2011). Angiomotin-like Proteins Associate with and Negatively Regulate YAP1. Journal of Biological Chemistry, 286(6), 4364-4370. doi:10.1074/jbc. C110.205401

Wang, Y., Justilien, V., Brennan, K. I., Jamieson, L., Murray, N. R., \& Fields, A. P. (2017). PKC[iota] regulates nuclear YAP1 localization and ovarian cancer tumorigenesis. Oncogene, 36(4), 534-545. doi:10.1038/onc.2016.224

Wells, C. D., Fawcett, J. P., Traweger, A., Yamanaka, Y., Goudreault1, M., Elder, K., .. . Pawson, T. (2006). A Rich1/ Amot Complex Regulates the Cdc42 GTPase and ApicalPolarity Proteins in Epithelial Cells. Cell, 125(3), 535-548

Wu, S., \& Zhang, Y. (2007). LOMETS: A local meta-threadingserver for protein structure prediction. Nucleic acids research, 35(10), 3375-3382. doi:10.1093/nar/gkm251

Xu, D., Jaroszewski, L., Li, Z., \& Godzik, A. (2013). FFAS3D: improving fold recognition by including optimized structural features and template re-ranking. Bioinformatics. doi:10.1093/bioinformatics/btt578

$\mathrm{Xu}$, J., \& Zhang, Y. (2010). How significant is a protein structure similarity with TM-score $=0.5$ ? Bioinformatics, 26(7), 889895. doi:10.1093/bioinformatics/btq066

Xu, Y., Seet, L. F., Hanson, B., \& Hong, W. (2001). The Phox homology (PX) domain, a new player in phosphoinositide signalling. Biochem. J., 350(3), 513-530.

Xu, Y., \& Xu, D. (2000). Protein threading using PROSPECT: Design and evaluation. Proteins: Structure, Function, and Bioinformatics, 40(3), 343-354. doi:10.1002/10970134(20000815)40:3<343::aid-prot10>3.0.co;2-s

Yan, R., Xu, D., Yang, J., Walker, S., \& Zhang, Y. (2013). A comparative assessment and analysis of 20 representative sequence alignment methods for protein structure prediction. Scientific reports, 3, 2619. doi:10.1038/srep02619

Yang, J., Yan, R., Roy, A., Xu, D., Poisson, J., \& Zhang, Y. (2015). The I-TASSER Suite: protein structure and function prediction. Nat Meth, 12(1), 7-8. doi:10.1038/nmeth.3213 http:// www.nature.com/nmeth/journal/v12/n1/abs/nmeth.3213. html\#supplementary-information

Yi, C., Shen, Z., Stemmer-Rachamimov, A., Dawany, N., Troutman, S., Showe, L. C., . . Kissil, J. L. (2013). The p130 Isoform of Angiomotin Is Required for Yap-Mediated Hepatic Epithelial Cell Proliferation and Tumorigenesis. Science signaling, 6(291), ra77-ra77. doi:10.1126/scisignal.2004060

Zhang, H., \& Fan, Q. (2015). MicroRNA-205 inhibits the proliferation and invasion of breast cancer by regulating AMOT expression. Oncology reports, 34(4), 2163-2170.
Zhang, Y. (2008). I-TASSER server for protein 3D structure prediction. BMC Bioinformatics, 9(40).

Zhang, Y. (2008). I-TASSER server for protein 3D structure prediction. BMC Bioinformatics, 9(1), 1-8. doi:10.1186/14712105-9-40

Zhang, Y., \& Skolnick, J. (2004). Scoring function for automated assessment of protein structure template quality. Proteins: Structure, Function, and Bioinformatics, 57(4), 702-710. doi:10.1002/prot.20264

Zhang, Y., \& Skolnick, J. (2007). Scoring function for automated assessment of protein structure template quality. Proteins: Structure, Function, and Bioinformatics, 68(4), 1020-1020. doi:10.1002/prot.21643

Zhao, B., Li, L., Lu, Q., Wang, L. H., Liu, C.-Y., Lei, Q., \& Guan, K.-L. (2011). Angiomotin is a novel Hippo pathway component that inhibits YAP oncoprotein. Genes \& Development, 25(1), 51-63. doi:10.1101/gad.2000111

Zheng, Y., Vertuani, S., Nyström, S., Audebert, S., Meijer, I., Tegnebratt, T., .. . Holmgren, L. (2009). Angiomotin-Like Protein 1 Controls Endothelial Polarity and Junction Stability During Sprouting Angiogenesis. Circulation Research, 105(3), 260-270. doi:10.1161/circresaha.109.195156

Zhou, H., \& Zhou, Y. (2004). Single-body residue-level knowledgebased energy score combined with sequence-profile and secondary structure information for fold recognition. Proteins: Structure, Function, and Bioinformatics, 55(4), 1005-1013. doi:10.1002/prot.20007

Zhou, H., \& Zhou, Y. (2005). Fold recognition by combining sequence profiles derived from evolution and from depthdependent structural alignment of fragments. Proteins: Structure, Function, and Bioinformatics, 58(2), 321-328. doi:10.1002/prot.20308 